\title{
Does milk intake promote prostate cancer initiation or progression via effects on insulin-like growth factors (IGFs)? A systematic review and meta-analysis
}

\author{
Sean Harrison ${ }^{1,2}$ - Rosie Lennon ${ }^{1} \cdot$ Jeff Holly $^{3} \cdot$ Julian P. T. Higgins $^{1,2} \cdot$ Mike Gardner $^{1,4} \cdot$ Claire Perks $^{3}$. \\ Tom Gaunt ${ }^{1,2} \cdot$ Vanessa Tan $^{1,2} \cdot$ Cath Borwick $^{1,5} \cdot$ Pauline Emmet $^{1} \cdot$ Mona Jeffreys $^{1} \cdot$ Kate Northstone $^{6}$. \\ Sabina Rinaldi ${ }^{7} \cdot$ Stephen Thomas $^{8} \cdot$ Suzanne D. Turner $^{9} \cdot$ Anna Pease $^{1} \cdot$ Vicky Vilenchick $^{1}$. \\ Richard M. Martin ${ }^{1,2,10} \cdot$ Sarah J. Lewis ${ }^{1,2}$
}

Received: 10 May 2016 / Accepted: 10 March 2017 / Published online: 30 March 2017

(c) The Author(s) 2017. This article is published with open access at Springerlink.com

\begin{abstract}
Purpose To establish whether the association between milk intake and prostate cancer operates via the insulinlike growth factor (IGF) pathway (including IGF-I, IGF-II, IGFBP-1, IGFBP-2, and IGFBP-3).

Methods Systematic review, collating data from all relevant studies examining associations of milk with IGF, and those examining associations of IGF with prostate cancer risk and progression. Data were extracted from experimental and observational studies conducted in either humans or animals, and analyzed using meta-analysis where possible, with summary data presented otherwise.

Results One hundred and seventy-two studies met the inclusion criteria: 31 examining the milk-IGF relationship; 132 examining the IGF-prostate cancer relationship in humans; and 10 animal studies examining the IGF-prostate cancer relationship. There was moderate evidence that
\end{abstract}

Sean Harrison and Rosie Lennon have contributed equally to this work, as have Richard M. Martin and Sarah J. Lewis.

Electronic supplementary material The online version of this article (doi:10.1007/s10552-017-0883-1) contains supplementary material, which is available to authorized users.

Sarah J. Lewis

s.j.lewis@bristol.ac.uk

1 School of Social and Community Medicine, University of Bristol, Bristol, UK

2 MRC Integrative Epidemiology Unit (IEU), University of Bristol, Bristol, UK

3 IGFs \& Metabolic Endocrinology Group, School of Clinical Sciences at North Bristol, Southmead Hospital, BS10 5NB Bristol, UK

4 Nuffield Department of Population Health, University of Oxford, Oxford, UK circulating IGF-I and IGFBP-3 increase with milk (and dairy protein) intake (an estimated standardized effect size of 0.10 SD increase in IGF-I and 0.05 SD in IGFBP-3 per $1 \mathrm{SD}$ increase in milk intake). There was moderate evidence that prostate cancer risk increased with IGF-I (Random effects meta-analysis OR per SD increase in IGF-I $1.09 ; 95 \%$ CI 1.03, 1.16; $n=51$ studies) and decreased with IGFBP-3 (OR 0.90; 0.83, 0.98; $n=39$ studies), but not with other growth factors. The IGFBP-3 -202A/C single nucleotide polymorphism was positively associated with prostate cancer (pooled $\mathrm{OR}$ for $\mathrm{A} / \mathrm{C}$ vs. $\mathrm{AA}=1.22 ; 95 \% \mathrm{CI} 0.84$, 1.79; OR for $\mathrm{C} / \mathrm{C}$ vs. $\mathrm{AA}=1.51 ; 1.03,2.21, n=8$ studies). No strong associations were observed for IGF-II, IGFBP-1 or IGFBP-2 with either milk intake or prostate cancer risk. There was little consistency within the data extracted from the small number of animal studies. There was additional evidence to suggest that the suppression of IGF-II can reduce tumor size, and contradictory evidence with regards to the effect of IGFBP-3 suppression on tumor progression. Conclusion IGF-I is a potential mechanism underlying the observed associations between milk intake and prostate cancer risk.

\section{Cardiff University, Cardiff, UK}

6 CLAHRC West, University of Bristol, Bristol, UK

7 International Agency for Research on Cancer, Lyon, France

School of Oral and Dental Sciences,, University of Bristol, Bristol, UK

9 Department of Pathology, University of Cambridge, Cambridge, UK

10 National Institute for Health Research Biomedical Research Unit in Nutrition, Diet and Lifestyle, University Hospitals Bristol NHS Foundation Trust and the University of Bristol, BS2 8AE Bristol, UK 
Keywords Prostate cancer - Insulin-like growth factors · Milk $\cdot$ Mechanistic pathway $\cdot$ Systematic review $\cdot$ Metaanalysis

\section{Introduction}

Dairy consumption, and in particular milk, has been implicated as a risk factor for prostate cancer, although results are inconsistent. The World Cancer Research Fund (WCRF)/ American Institute for Cancer Research (AICR) concluded in their 2014 expert report that there is limited evidence that milk increases risk [1]: the synthesized results of 15 of the 21 studies identified as examining the association between dairy products and prostate cancer risk showed a $7 \%$ increased risk per $400 \mathrm{~g}$ of dairy products consumed per day (RR 1.07, 95\% CI 1.02-1.12). However, observational studies have been hindered by milk consumption being recorded semi-quantitatively in some studies, with large differences between individuals in the same group, and therefore subject to attenuation of effects by measurement error. In addition, associations of milk intake with prostate cancer are susceptible to confounding by other diet and lifestyle factors.

Evidence to support the causality of observed positive associations of milk intake with prostate cancer could come from basic experimental studies. For example, a recent study [2] showed that milk stimulates the growth of prostate cancer cells in culture. In addition, evidence of underlying mechanisms by which milk causes prostate cancer may shed some light on whether observational findings are likely to be accurate. However, some way of systematically collating and synthesizing data from such disparate sources is required in order to avoid the selective interpretation of evidence.

Our overall objective in this work was to assemble the worldwide literature from human, animal, and genetic models to investigate whether any association between milk consumption and prostate cancer initiation or progression acts via the IGF pathway. The review was undertaken as a case study in support of a novel framework for reviewing mechanistic studies of exposures and cancer; the milk-prostate cancer association was not considered as the WCRF have already synthesised this literature. The framework was commissioned by WCRF UK, as an extension of their Continuous Update of the 2007 Report [1].

Several mechanisms have been hypothesised by which milk could promote prostate cancer. First, increased calcium intake in people with high milk consumption may suppress the conversion of $25(\mathrm{OH})$ vitamin $\mathrm{D}$ to $1,25(\mathrm{OH}) 2$ vitamin $\mathrm{D}$, which has antiproliferative effects on human prostate cancer cells [3]. Second, milk is a rich source of oestrogens [4], which are associated with prostate cancer, although the mechanism of action is poorly understood [5]. Furthermore, the nutritionally regulated (including by milk intake [6]) insulin-like growth factor (IGF) signaling pathway has been highlighted in a number of studies as a probable factor in prostate cancer ( $\mathrm{PCa}$ ) initiation and progression [7-9].

Relevant mechanistic studies will frequently have an intermediate phenotype (in this case the IGF system) rather than cancer as an outcome, or the intermediate phenotype as the exposure for a cancer outcome. Therefore, we separately identified studies that linked our exposure of interest (milk) to the intermediate phenotype, and studies that linked the same intermediate phenotype to prostate cancer initiation or progression. Data from each evidence stream (human, animal, and genetic models) were critically appraised using specific risk of bias (RoB) protocols and graded using the Grading of Recommendations Assessment, Development, and Evaluation (GRADE) tool. By combining the evidence from each study type and using strict RoB and GRADE protocols to ensure the inclusion of high-quality data only, our aim was to provide a comprehensive review of the milk-PCa relationship, focusing on IGF as a specific intermediate phenotype.

\section{Materials and methods}

\section{Data sources}

We carried out two searches to identify studies that investigated (i) associations between milk intake and IGF levels (milk-IGF); and (ii) associations between IGF levels and prostate cancer (PCa) outcomes (IGF-PCa). MEDLINE (1950-March 2014), EMBASE (1980-March 2014), BIOSIS (1969-March 2014) and CINAHL (1981-March 2014) were systematically searched. Searches were performed using key words (BIOSIS) or a combination of key words and subject headings (MEDLINE, EMBASE, and CINAHL). Full search terms are included in Supplementary Boxes 1-3.

\section{Inclusion and exclusion criteria}

We included original articles published in peer-reviewed journals (including supplements and meeting abstracts); reviews, books, commentaries, and letters were excluded. We included randomized controlled trials (RCTs), case-control, cohort, non-randomized experimental, and case-series studies in humans, as well as all animal studies, with the exception of those that used a known carcinogen alongside the exposure. This decision was based on the relevance of carcinogenic-initiated cancers within the context of addressing whether milk causes prostate cancer initiation or its progression. We included both transgenic and xenograft animal models; although transgenic models were considered to be more relevant within a human context, xenograft models may give some insight into the biological 
plausibility of the mechanism of action. Animal studies that only presented cell line data or used hallmarks of cancer as the outcome [10] were analyzed separately; thus the results are not presented here. There were no language restrictions.

\section{Milk-IGF specific criteria}

We included all papers that investigated associations of dairy and milk intake with IGFs and IGFBPs. Outcomes of interest were serum or plasma levels of IGF-I, IGF-II, and IGF binding proteins (IGFBP-1, -2, and -3). Exposures of interest were milk or milk products, including dairy protein or dairy product intake. Since different milk products contain different amounts of water and other substances, they were considered both separately and together so that any differences between the exposures could be observed. We included both RCTs and observational studies. The primary exposure of interest within this analysis was cow's milk as a dietary environmental factor in relation to $\mathrm{PCa}$ risk; therefore, we excluded studies where the exposure was human breast milk, colostrum, soy milk or formula milk.

\section{IGF-Prostate Cancer specific criteria}

We included all papers that measured the association between the IGF pathway and prostate cancer outcomes. Exposures of interest were serum or plasma levels of IGFI, IGF-II, and IGF binding proteins (IGFBPs)-1, -2, and -3; expression levels of IGF-I, IGF-II, IGFBP-1, -2, and -3; IGF-I receptor (R), IGF-IIR genes and any other genes (or specific single nucleotide polymorphisms [SNPs]) with 'IGF' as part of the gene name and that were part of the IGF pathway. Outcomes of interest included prostate cancer incidence or prevalence, measures of progression (biochemical recurrence, local or distal metastases), and prostate cancerspecific mortality. We included studies using healthy or benign prostatic hyperplasia (BPH) control subjects. We excluded papers if PCa was not a defined outcome.

\section{Data extraction}

After papers (milk-IGF and IGF-PCa) had been identified and collated, exact duplicates were excluded. Titles, author names, page numbers, years of publication, and journal names were analyzed to exclude any remaining duplicates that had different entries in multiple databases due to typographical errors or reference style. The abstracts of all remaining papers were retrieved and independently screened by two of four possible assessors (SH, VV, AP, MG); where no abstract was available, or if the abstract provided insufficient information to inform a screening decision, the full text was retrieved for review. Any discrepancies between the two assessors were resolved by a third assessor.
Data were independently extracted in duplicate for each study (SH, RL), with disagreements resolved by discussion. Data extracted for all study types included details of study or model design, study population (location and sample size), exposure or intervention, outcome, statistical measure (including details of any model adjustments), and effect estimates (including mean values, standard deviation [SD], $\mathrm{P}$ values, and odds ratios [OR] with any corresponding 95\% confidence intervals $[\mathrm{CI}]$ as a continuous measure or by quantiles). For each study type (human studies [milk-IGF, IGF-PCa] or animal models [IGF-PCa]), specific data were also collected (see Box1).

Box 1 Differences in data extracted for each study type

\begin{tabular}{lc}
\hline Milk-IGF & IGF-prostate cancer \\
\hline Human studies & \\
$\begin{array}{c}\text { Study design: RCT, cross- } \\
\text { sectional, cohort }\end{array}$ & Study design: cohort, nested \\
Intervention: milk, dairy prod- & Retrospective or prospective \\
uct, dairy protein intake & ascertainment of outcome with \\
Outcome: type of IGF, IGFBP & respect to exposure measure- \\
Measure of exposure (units) & ment \\
Sample size & Intermediate phenotype: type \\
Average age of subjects & of IGF and IGFBP, name of \\
Percentage of males in study & genes/SNPs/allele/number of \\
Method of diet assessment & repeats \\
Length of follow-up & Study category: IGF levels, \\
Ethnicity & genetic, supporting evidence \\
& Control source (population, hos- \\
& pital, population-based cohort, \\
& trial-based cohort) \\
& Control type (healthy, BPH, \\
mixed BPH, and healthy) \\
Sample type (serum, plasma) \\
Method of exposure measure- \\
ment \\
Age of cases and controls \\
(including where possible, age \\
at diagnosis) \\
Time between sample collection \\
and analysis \\
PSA-detected or clinically \\
detected study populations \\
Mid-year of recruitment \\
Study name \\
Ethnicity \\
\end{tabular}

Animal studies

All IGF-PCa animal studies

Model design: transgenic, xenograft

Outcome: tumor biometrics (various), hallmarks of cancer [10]

Type of experimental and control models used

Length of follow-up

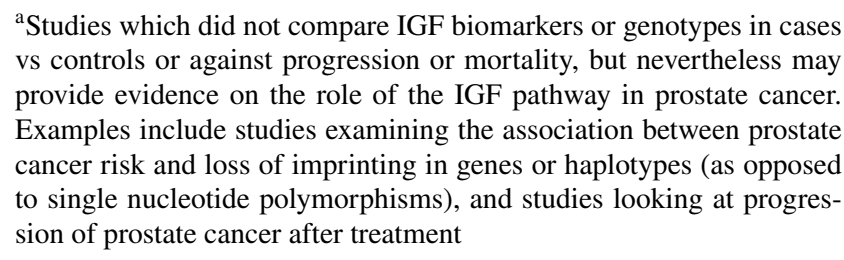




\section{IGF-Prostate cancer studies}

To minimize the risk of reverse causation (i.e., the secondary effects of PCa on IGF levels rather than the causal effects of IGF levels on PCa), we pragmatically classified human studies assessing IGF-PCa as prospective if there was a mean of 2 years or more between the collection of samples and diagnosis; otherwise they were classified as retrospective. Where the time between sample collection and diagnosis was unclear, we conservatively classified the studies as retrospective. This classification may differ from how the studies were classified by the authors in the original publication.

For papers presenting data in several ways the order of choosing the data to be synthesized was (i) reported coefficients (log odds ratio [OR] or risk ratio per unit increase in exposure); (ii) quantile data (ORs stratified by quantiles of IGF) and (iii) continuous data presented as mean or median differences. We extracted data that were fully adjusted up to, but not including, mutual adjustment for a different growth factor (i.e., IGF-I adjusted for IGFBP-3 and vice versa). If more than one publication or study presented data on the same IGF biomarker from the same cohort, we extracted data from the study with the largest sample size.

During extraction, we divided human IGF-PCa studies into three categories that provided data on (i) the association between circulating levels of IGF or IGFBPs, 'IGF level' studies and prostate cancer outcome; (ii) IGF or IGFBP genes or SNPs, 'genetic' studies; and (iii) studies which provided neither (i) or (ii), but presented data relevant to the relationship between the IGF pathway and PCa outcomes, termed as 'supporting evidence.' Studies examining free IGF levels, as opposed to total IGF levels, were not amenable to meta-analysis as they could not be combined with total IGF levels and there were too few papers to meta-analyze alone. As such, studies examining free IGF levels were included in supporting evidence.

\section{Milk-IGF studies}

We extracted $p$ values and sample sizes from all studies. If $p$ values were not presented, 95\% CIs and effect estimates were used to estimate the $p$ value. Data for males were extracted in preference to females (because the ultimate outcome of interest was prostate cancer), followed by combined data, then female only data.

\section{Statistical analyses}

\section{Milk-IGF data}

The main difficulty in combining all studies that examined the relationships of milk, dairy products, and dairy proteins with IGFs and IGFBPs was the degree of heterogeneity between these studies. Study designs ranged from RCTs conducted over decades to short-term observational studies; the exposures (milk, dairy protein, and dairy products) were both different and measured differently between studies; and study participants varied in age, ethnicity, and location. In addition, effect estimates were provided in different formats, such as percentage increases or ORs, often with too little information to estimate a standardized effect estimate.

We generated albatross plots [11] for each outcome to best interpret the results. An albatross plot is a scatter plot of study sample sizes against two-sided $p$ values, with results separated according to the observed direction of effect. The albatross plot allows the $p$ values to be interpreted in the context of the study sample size. Small studies appear toward the bottom of the plot and large studies toward the top. Different exposures are drawn using different markers to facilitate identification of subgroup effects. Effect contours are superimposed on the plot to give an indication of the magnitude of effect both for individual studies, and for the association as a whole.

To provide additional information, a meta-analysis of $\mathrm{P}$ values was conducted using Stouffer's $Z$ score method of combining $\mathrm{P}$ values [12]; the one-tailed $\mathrm{P}$ value for the most common direction of effect across studies for each IGF was used to calculate the one-tailed combined $p$ value across studies for each IGF.

\section{IGF-Prostate cancer data}

\section{Types of data used}

To compare data from multiple studies that examined relationships of growth factors with prostate cancer, we calculated the log OR per standard deviation (SD) increase in exposure, as previously described in Rowlands et al. [8]. The log OR per unit increase in exposure for studies presenting results as a difference in means between cases and controls was calculated using the method presented by Chêne and Thompson [13]. For studies presenting results within quantiles of exposure, the mean or median exposure was used in each quantile (if reported), and the log OR per unit increase in exposure was calculated using the method presented by Greenland and Longnecker [14], using the 'glst' command in Stata [15]. When the mean or median in each quantile was not reported but instead a range of exposures in each group was, the mean exposure was estimated in each quantile using the method presented by Chêne and Thompson [13] (assuming a normal distribution of the exposure in the population). When no mean, median or range was reported, a normal distribution was assumed 
based on the mean and SD of the group used to generate the quantiles (usually the controls). This distribution was used to calculate the quantile range, and thus the mean of each quantile. If only subgroup analyses were presented and not an overall case versus control group analysis, the subgroups were combined statistically by calculating pooled means and SDs. The log ORs per unit increase and their standard errors were converted to a per SD increase by multiplying by the SD of the exposure. For quantile data, the SD was calculated using the method presented by Chêne and Thompson [13].

As in the Rowlands meta-analysis [8], a linear relationship between growth factors and prostate cancer was assumed, which can result in a different OR to a highest versus lowest quantile analysis. However, this method allowed the use of the middle quantiles of data, increasing the amount of available data.

\section{Random effects and fixed effect meta-analyses}

We performed random effects and fixed effect meta-analyses on all growth factors to calculate summary OR estimates, using the 'metan' Stata command [16]. We calculated the $\mathrm{I}^{2}$ statistic as a quantitative measure of the degree of inconsistency across studies [17]. Small study effects were assessed by inspection of funnel plots and computation of Egger and Begg tests [18, 19].

There was substantial inconsistency across studies in the IGF-PCa analysis $\left(I^{2}>65 \%\right.$ for all growth factors). Therefore, our primary results are from random effects models throughout this paper; we also present fixed effect results for comparison.

\section{Subgroup analyses}

To investigate whether growth factors were associated with advanced prostate cancers, we conducted a separate metaanalysis using data from studies that examined this outcome. The definition of advanced prostate cancers varied across studies; the combined definition of 'advanced' thus extends to non-localized cancers, Gleason score 7+ cancers, metastasized cancers, 'high grade' cancers (the definition of which varied between studies) or 'aggressive' cancers (which were a combination of advanced stage and high grade).

We produced forest plots for all growth factor and both prostate cancer outcome (all and advanced) analyses; these plots were stratified by prospective and retrospective studies, and PSA-detected and clinically detected studies. The difference between subgroup estimates was explored using the method of Altman and Bland [20].

\section{Genetic data}

Although many studies reported associations between various SNPs and prostate cancer, only two genetic variants were examined by a sufficient number of studies to allow us to conduct meta-analyses: IGF-I CA repeats, and IGFBP-3 $-202 \mathrm{~A} / \mathrm{C}$ polymorphisms. We included studies which presented results in a combinable way: for IGF-I CA repeats, $19 / \mathrm{X}$ and $\mathrm{X} / \mathrm{X}$ were both compared against 19/19 repeats in separate analyses, where $\mathrm{X}$ was anything other than 19 . For IGFBP-3 -202 A/C polymorphism, A/C and C/C were both compared against $\mathrm{A} / \mathrm{A}$ in separate analyses. If data were presented in the opposite direction, i.e., $\mathrm{A} / \mathrm{C}$ and $\mathrm{A} / \mathrm{A}$ against $\mathrm{C} / \mathrm{C}$, we transformed the results to allow these to be combined with other data. The meta-analyses for these genotypes were conducted in the same manner as in the IGF-PCa studies with forest and funnel plots produced, but not grouped by prospective/retrospective, as an individual's genotypes do not change over time, and therefore should not be susceptible to reverse causation.

\section{Risk of bias (RoB) and GRADE assessments}

Due to the variety of studies included within the metaanalysis and the need for consistent risk of bias assessment, we developed a tool to determine the overall risk of bias for each study using the categories of assessment from a draft of the ROBINS-I tool [21], and the questions to aid in assessing risk of bias from the CASP case-control and cohort questionnaires [22, 23]. Bias was assessed in six categories: Confounding, selection of participants, missing data, outcome measurement, exposure measurement, and results' reporting. Each category contained questions designed to help assess the risk of bias; these varied depending on the study type (e.g., animal, human, genetic) and design (e.g., cohort, RCT, case-control) (Supplementary Box 4). An overall and category-specific risk of biases were assigned; either low, moderate, serious, critical, or unclear.

On the basis that circulating IGF levels increase with age from birth to young adulthood and then gradually decline into old age, any studies which did not age-match cases and controls or adjust for age within the analysis, and presented a difference of 5 or more years between the mean age of cases and controls, were categorized as critical RoB due to confounding and excluded from the analysis. In addition, all observational studies that investigated serum levels of IGF in relation to PCa risk were given a moderate RoB status as a minimum, as it is unlikely that all confounding factors could be fully controlled for within observational designs. The majority of the human IGF-PCa cohort papers did not provide information on missing data 
with regards to patients lost at follow-up, therefore these papers were considered to have at least a moderate RoB due to missing data.

All milk-IGF studies that used food frequency questionnaires, or used diet assessments involving information recall, were also given a moderate RoB rating as a minimum due to measurement error when dietary recall is used as the only measure of exposure.

For milk studies, if only one RoB sub-category was found to be unclear, the level of bias the sub-category could have caused was taken into consideration. For example, confounding could have a large impact on risk of bias, and therefore an unclear risk of bias in confounding would be assumed to be serious risk of bias. Conversely, results' reporting has a relatively smaller impact on risk of bias, and therefore unclear risk of bias would be assumed to be moderate risk of bias. The overall risk of bias for a study was based on the sub-category with the largest risk of bias. Studies determined to have a critical risk of bias were excluded before analysis.

The GRADE rating for each exposure/outcome pair was calculated as per the GRADE protocol [24]. The RoB status of each paper was used to inform the GRADE rating for each collection of papers within a study category (e.g., animal IGF-PCa). The overall GRADE rating was used to provide a measure of overall quality of the evidence provided by the results.

\section{Results}

Systematic searches of all four online databases identified 7,239 papers; 3,025 cross-database duplicates were removed, leaving 4,214 papers. After abstract screening, 728 papers remained for full text review, including one additional paper from Rowlands et al. [8] that was not identified within the original search [25]. Of these, 172 papers met the inclusion criteria and were taken forward for data extraction (Fig. 1): 31 papers (representing 31 independent studies) examining the milk-IGF relationship; 132 papers (representing 125 studies) examining the IGF-prostate cancer relationship in humans; and ten papers (representing ten studies) examining the IGF-prostate cancer relationship in animals. One study had data relevant to both milk-IGF and IGF-PCa analyses [26].

None of the 31 milk-IGF studies were excluded due to RoB, and all were included in at least one albatross plot and narrative synthesis of different IGFs, except for two studies $[27,28]$ that looked at qualitatively different outcomes, which were excluded from the albatross plots and considered separately in the narrative synthesis. The total number of studies looking at each type of IGF was as follows (the two studies excluded from albatross plots shown in brackets): IGF-I, $n=28(+2)$; IGF-II, $n=2$ $(+1)$; IGFBP-1, $n=2$; IGFBP-2, $n=2(+1)$; IGFBP-3, $n=15(+2)$. Three studies stratified results by ethnicity; the ethnicity subgroups were considered as separate data points in the albatross plots [29-31].

Of the studies included in the milk-IGF analysis, two had serious RoB (both retrospective cross-sectional studies) $[32,33] ; 18$ had moderate RoB (two prospective cohort studies; 16 retrospective cross-sectional studies) [27, 31, 34-49]; one had low RoB (non-randomized trial) [30]; and nine had unclear RoB (four RCTs, one non-randomized trial, three prospective cohorts, and one retrospective cross-sectional study) [28, 29, 50-57].

No animal milk-IGF studies were included due to irrelevant exposures or outcomes of interest; the majority of animals were exposed to colostrum intake within the first 6 months of life as part of study designs.

Of the 132 human IGF-PCa studies, 89 had serum level IGF data available for meta-analysis; the remaining 43 studies were considered as supporting evidence as they did not contain any data amenable to meta-analysis [58-100]. One study was considered as supporting evidence since it presented data for free IGF-I in relation to PCa risk, rather than total serum levels of IGF-I [75].

Of the 89 studies with data for meta-analysis, 16 had serious RoB (all retrospective) [101-116], 47 had moderate RoB (23 prospective, 24 retrospective) [8, 26, 34, 117-160], eight had low RoB (all genetic only) [161-168] and seven had unclear RoB (five genetic only, two retrospective) [25, 169-174]. Eleven observational studies were excluded from the meta-analysis due to critical RoB (one prospective, one genetic, and nine retrospective [175-185]).

Seven studies were excluded from the meta-analysis as they presented data from the same group of participants with the same exposure and outcome variables as other included studies that contained more information (e.g., more participants) [34, 122, 153, 156-160], leaving 71 unique studies for meta-analysis; 58 studies examining serum IGF levels (IGF-I: 51 studies; IGF-II: 10 studies; IGFBP-1: 4 studies; IGFBP-2: 6 studies; IGFBP-3: 39 studies; IGF-I and IGFBP-3 Advanced PCa: 12 studies) and 18 examining IGF genetic data (IGF-I (CA)n repeats: 5 studies; IGFBP-3 -202 A/C SNP: 8 studies; other SNPs: 11 studies). Three papers did not contain enough information in the paper to calculate an OR [25, 151, 174]; therefore data from the previous Rowlands meta-analysis were used [8], as Rowlands contacted the study authors for more information as part of the data extraction protocol.

Eight animal IGF-PCa studies were included within the animal analysis [186-193], and two animal studies were 

ing the inclusion and exclusion process during the meta-analysis and the number of papers categorized into each study type for milk-IGF and IGF-PCa
Fig. 1 Flow diagram depict-

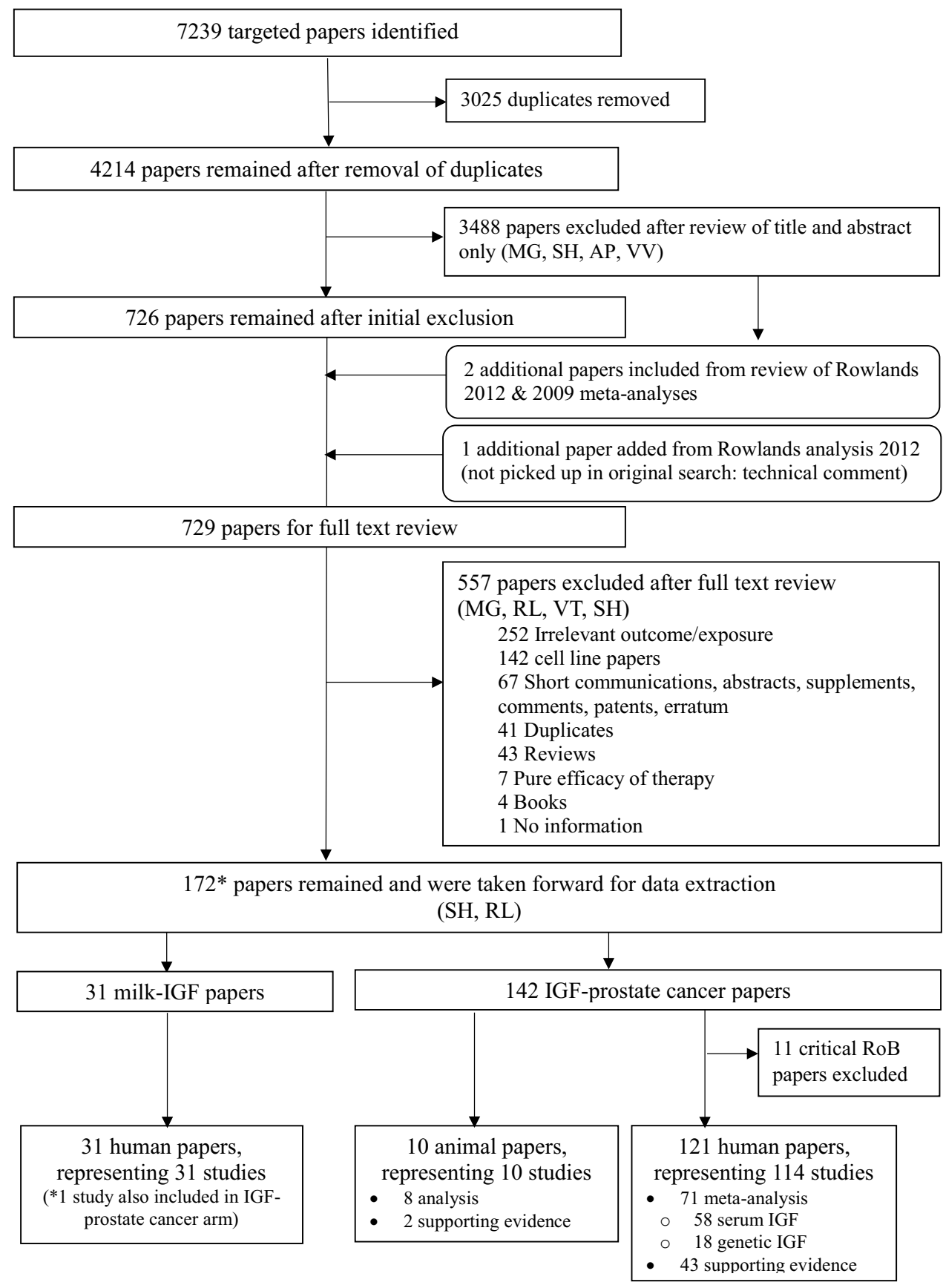

\section{Milk-IGF: human studies}

included in supporting evidence [194, 195]; these studies did not have enough information to extract an effect estimate or $\mathrm{P}$ value. The overall risk of bias in all animal studies was unclear.

An infographic displaying the main results of the human milk to IGF and IGF to PCa studies is presented in Fig. 2, showing the combined $\mathrm{P}$ values for the associations between milk and IGFs, and IGFs and PCa risk (including advanced PCa risk), the direction of effect and the total number of participants from all studies.
Table 1 shows data extracted from studies examining the milk-IGF association. In general, studies examined the quantity of milk or dairy consumed through a food record or food frequency questionnaire, and used servings/weight of milk/dairy consumed per day/week, as the exposure (either categorically or continuously). The outcome (IGF levels) was measured using blood draws. The majority of studies were cross-sectional; prospective studies had a follow-up ranging from 1 week to 65 years. Interventional 


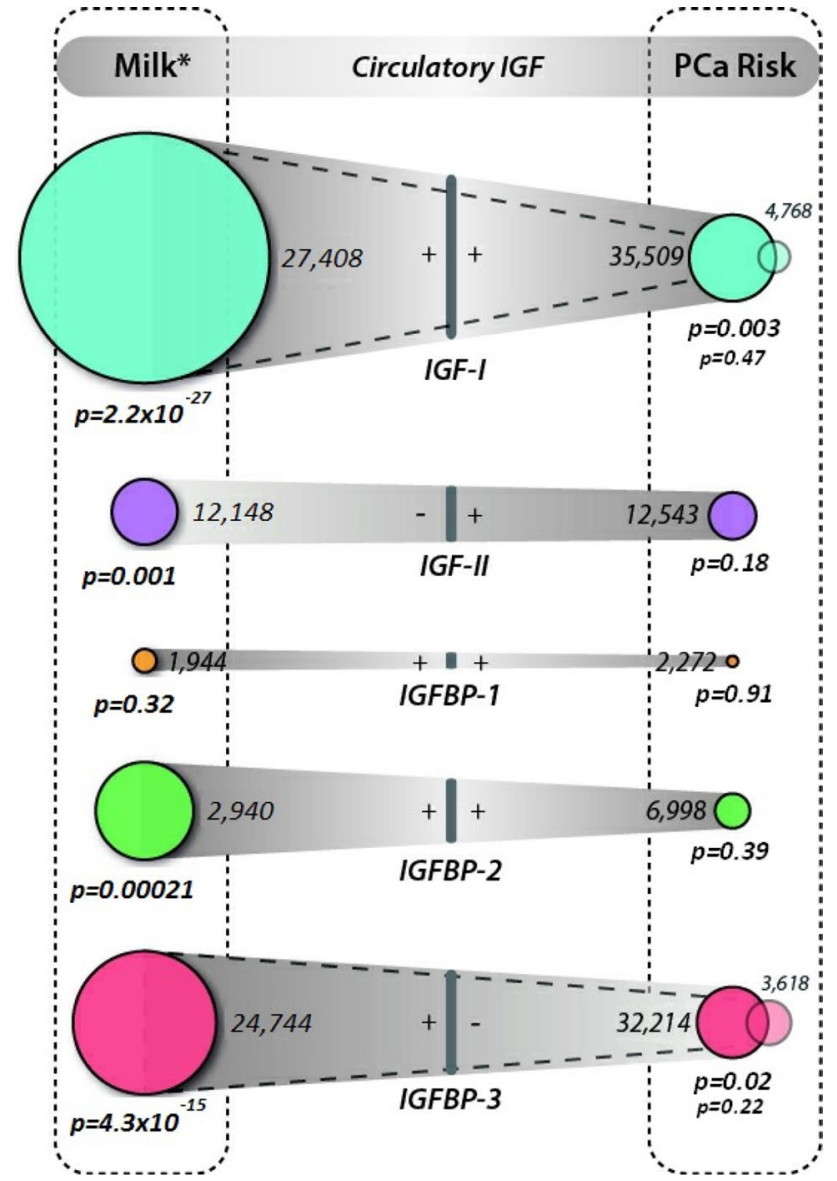

Fig. 2 Infographic to illustrate overall associations between milk intake and PCa risk (including advanced risk for IGF-I and IGFBP3). Notes: numbers next to the circles indicate the total number of participants across all studies, the size of each circle is proportionate to the $p$ value (larger circles indicate lower $p$ values), the "+" and "_" symbols indicate the direction of effect, the two semi-transparent circles in IGF-I and IGFBP-3 PCa Risk indicate advanced PCa risk (with associated $p$ values the lower of the two $p$ values), and $p$ values are all calculated using Stouffer's $Z$ score method of combining $p$ values. *Milk is used as a collective term for milk, dairy products and dairy proteins

studies generally supplemented the diet of the participants, rather than depriving one group of milk/dairy. The age range of participants when the outcome was measured varied between 2 and 86 years; the majority of studies focussed on Caucasians.

Data extracted from the 31 milk-IGF studies were unsuitable for standard meta-analysis methods of combining effect sizes due to high levels of heterogeneity and differences in effect estimate formats (Tables 1, 2, 3). The studies investigated a range of exposures (including milk, milk beverages, dairy protein, and dairy products) that were quantified by a number of measures (such as density intake [g/1,000 kcal/day], percentage of energy intake and servings per day and grams per day).
Albatross plots were used to assimilate the data and visual inspection was used to provide an estimated standardized effect estimate and a range of possible effect estimates for each outcome (Table 4). The effect estimates are not precise and are intended only as an indication of the magnitude of the effect estimate; a range of possible estimates is provided to highlight this fact. We present all standardized effect estimates for the milk-IGF association as the standard deviation (SD) increase in IGF protein per one standard deviation increase in the measure of exposure. One SD of milk varies across studies, especially as studies differ in presentation of milk units (e.g., grams per day, milliliters per day, portions per day). However, Hoppe [53] and Rogers [43] report that one SD is about $200 \mathrm{ml}$, and Hrolfsdottir [54] reports one SD is about $370 \mathrm{ml}$, so although an exact amount of milk per SD cannot be determined, an estimate between 200 and $350 \mathrm{ml}$ seems appropriate.

Two studies (Martin [27] and Ben-Shlomo [28]) studied the effects of milk intake in childhood and IGF-I and IGFBP3 levels in adulthood, and were considered separately. The Martin study also included IGF-II and IGFBP2, and the results of these were also considered separately.

\section{The association between milk and IGF-I}

Of the 31 data points (from 28 studies) included in the main IGF-I analysis, 29 data points showed positive associations of milk and dairy intake with IGF-I levels compared to two data points that showed negative or null associations. The estimated standardized effect size was 0.10 SD increase in IGF-I per $1 \mathrm{SD}$ increase in milk (estimated range $0.05-0.25$ SDs), from observation of the albatross plot (Fig. 3a). The combined $p$ value for a positive association was $2.2 \times 10^{-27}$. All studies with non-Caucasian subjects displayed a positive association between milk intake and $\mathrm{PCa}$ risk; in particular, two studies $[30,52]$ had $p$ values of 0.0001 and 0.001 , respectively, and both studies had a sample size of less than 100 . When considering only Caucasians, the overall impression from the albatross plot did not change; the effect estimate was still considered to be around 0.10 SD.

Of the 31 data points, 18 had an estimated standardized effect size between 0.05 and 0.25 SDs and four had an effect size of more than $0.25 \mathrm{SD}$. Eleven of these data points $(61 \%)$ used milk as an exposure, including two that had an estimated standardized effect size of more than 0.25 SD [30, 53].

When considering studies that examined the association between milk and IGF-I, the 31 data points (from 28 studies) showed consistency in their direction of effect, as all but two associations seen were positive.

The largest effect was seen in the Rich-Edwards study [30], where 26 Mongolian children, who had a very low 


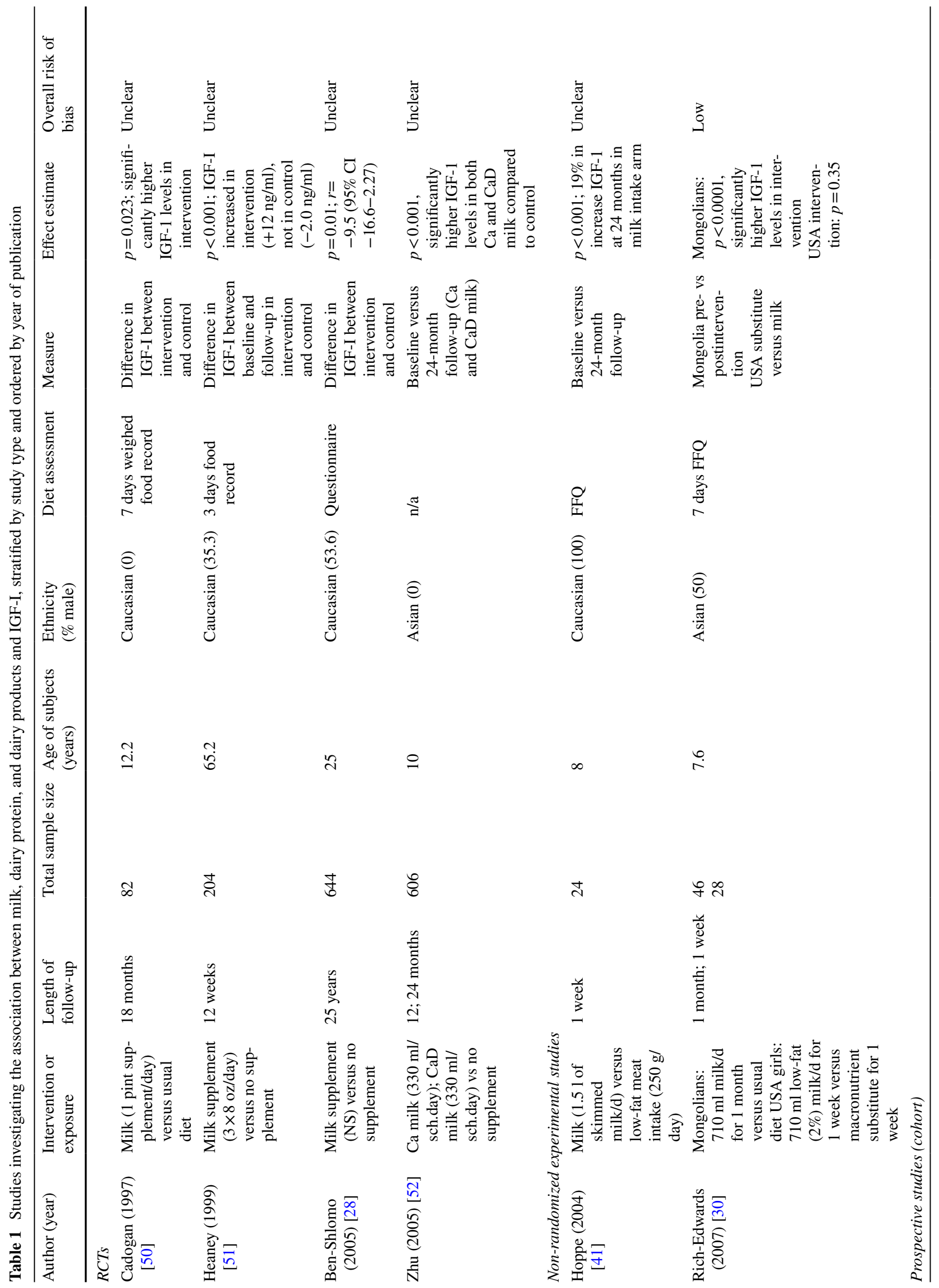




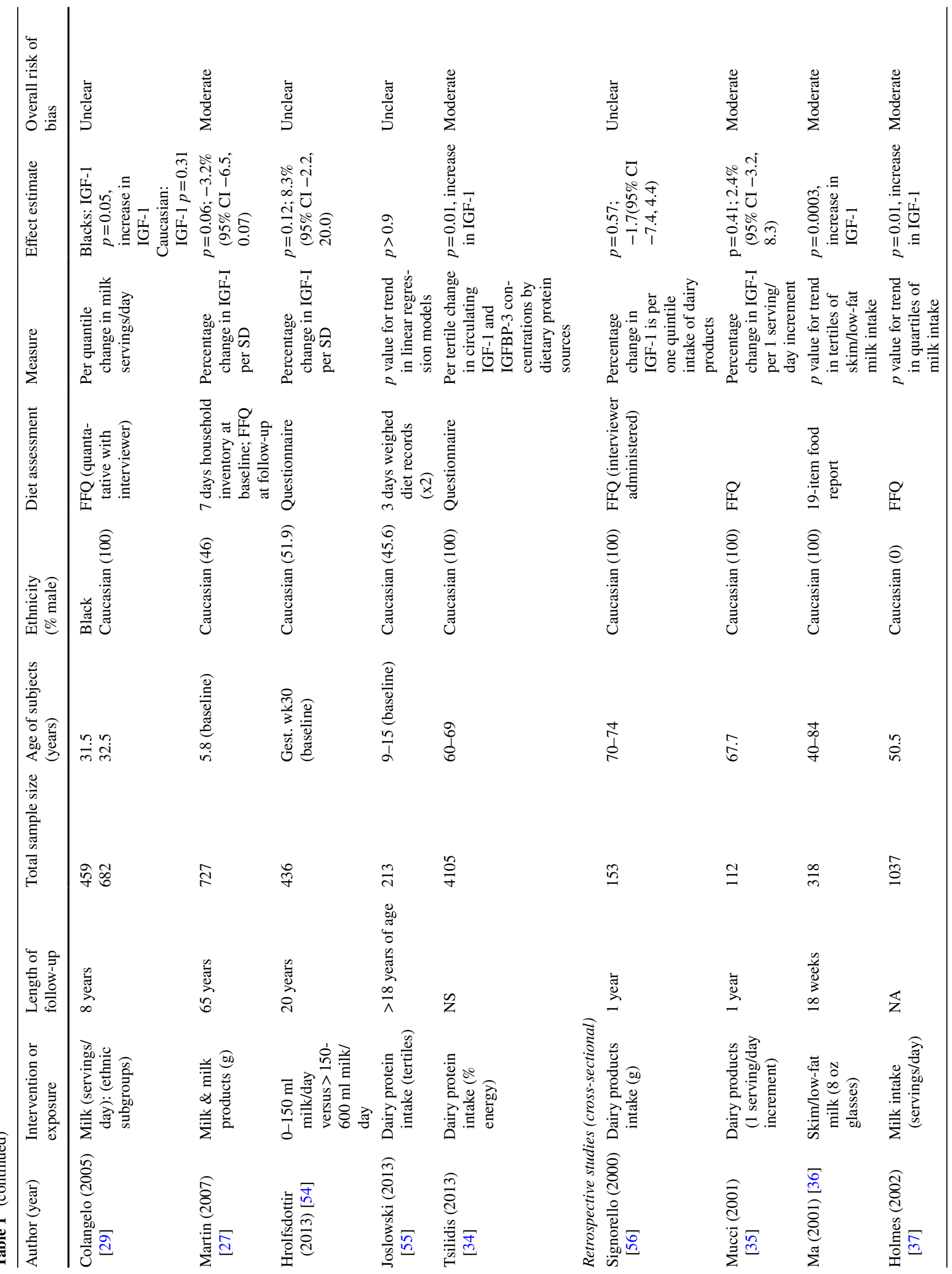




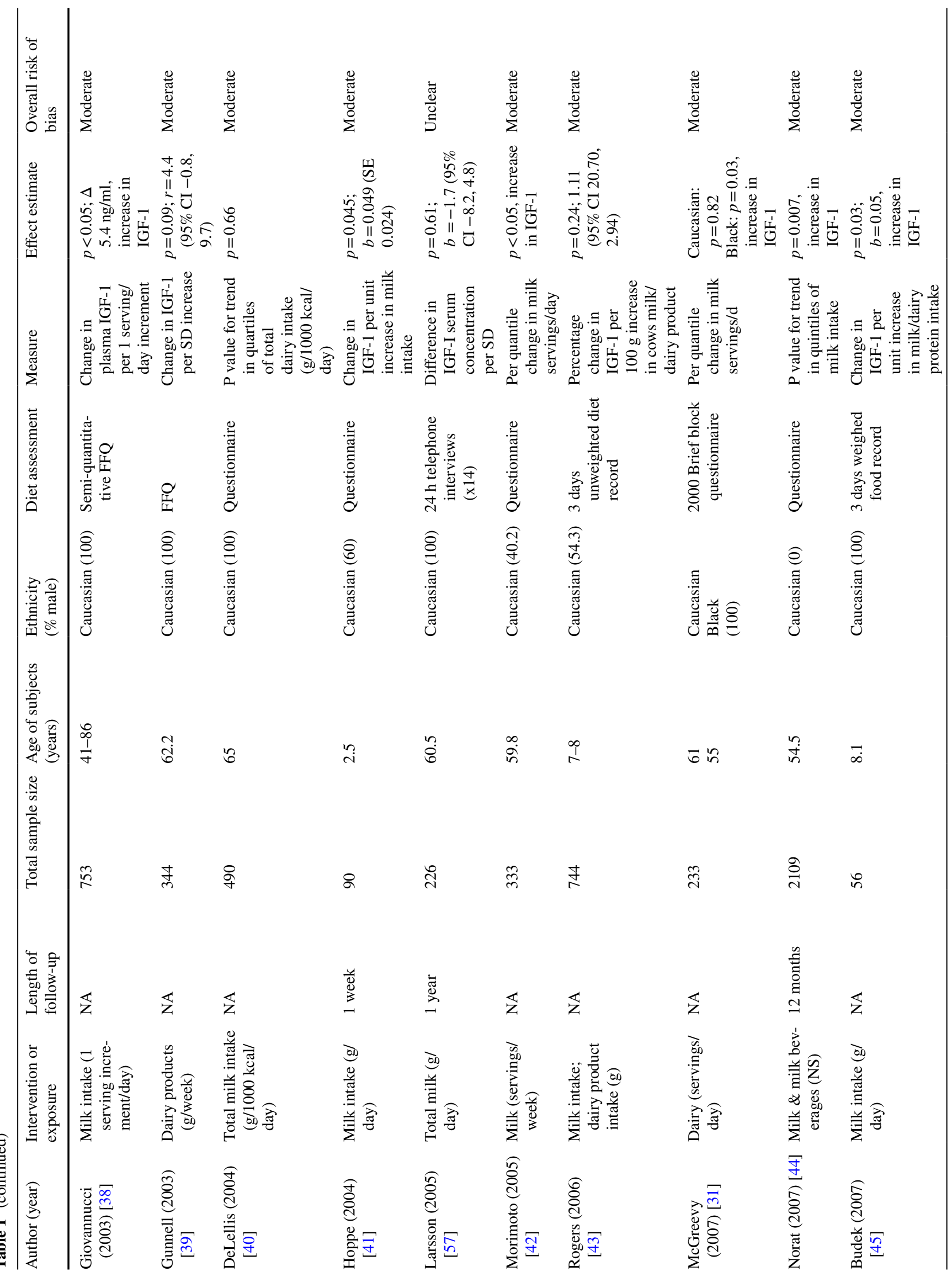




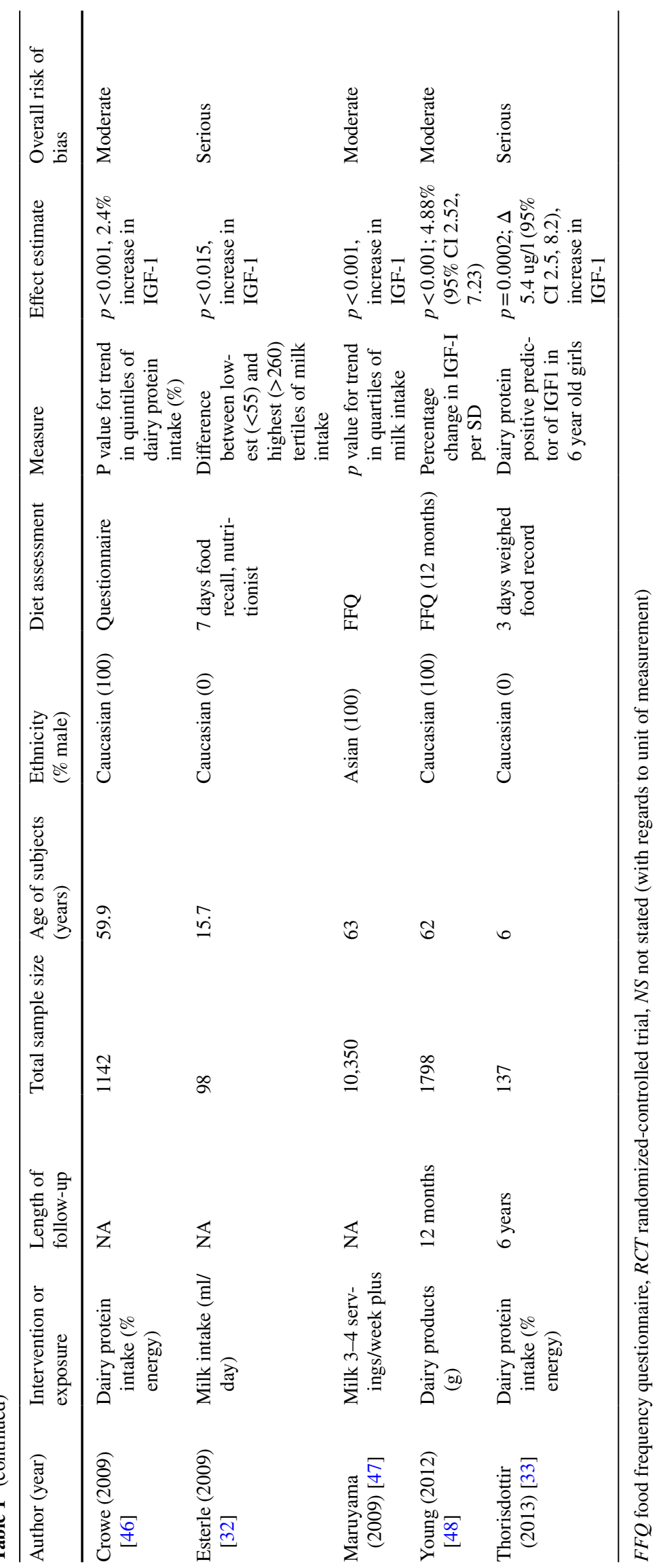




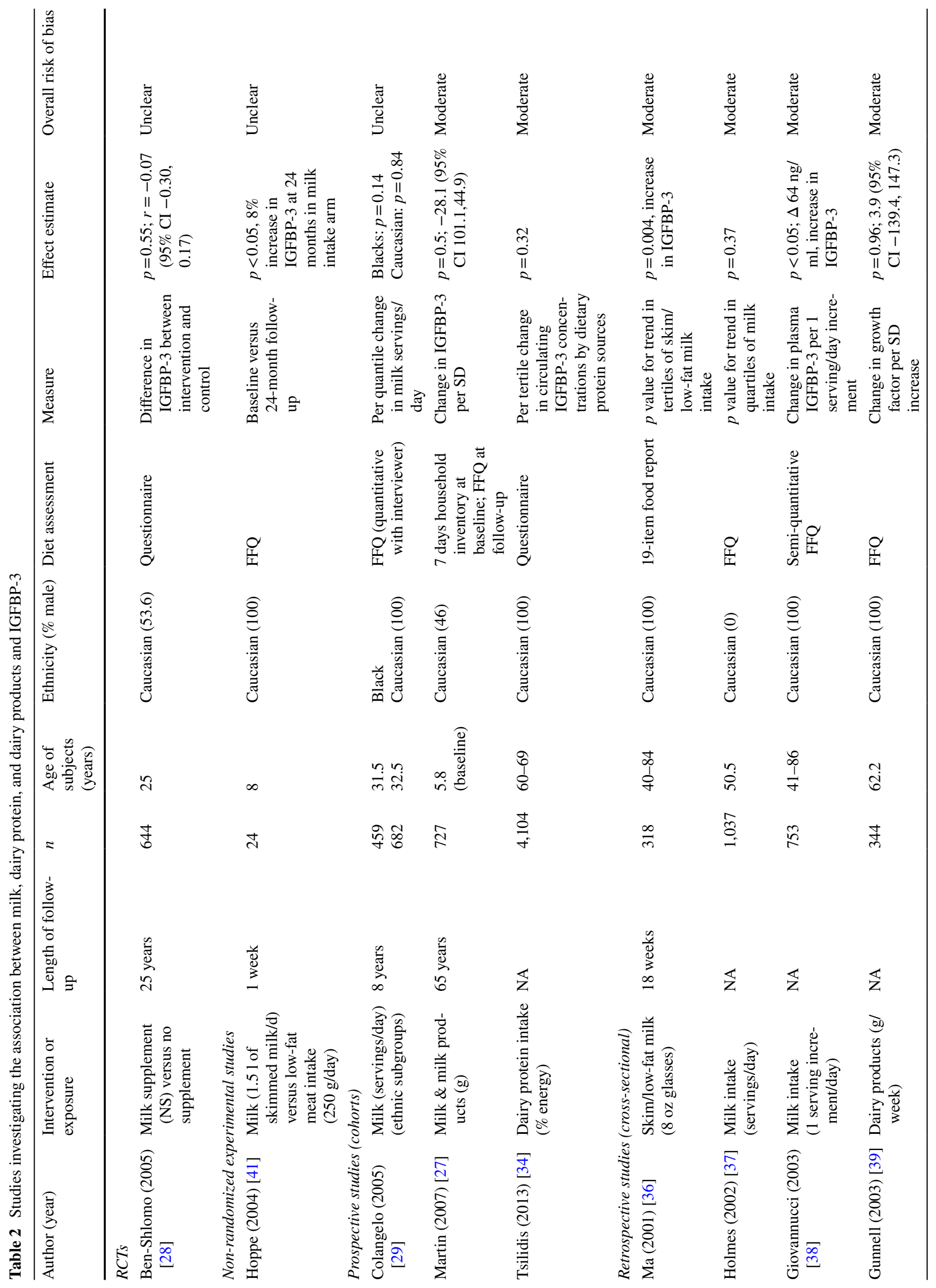




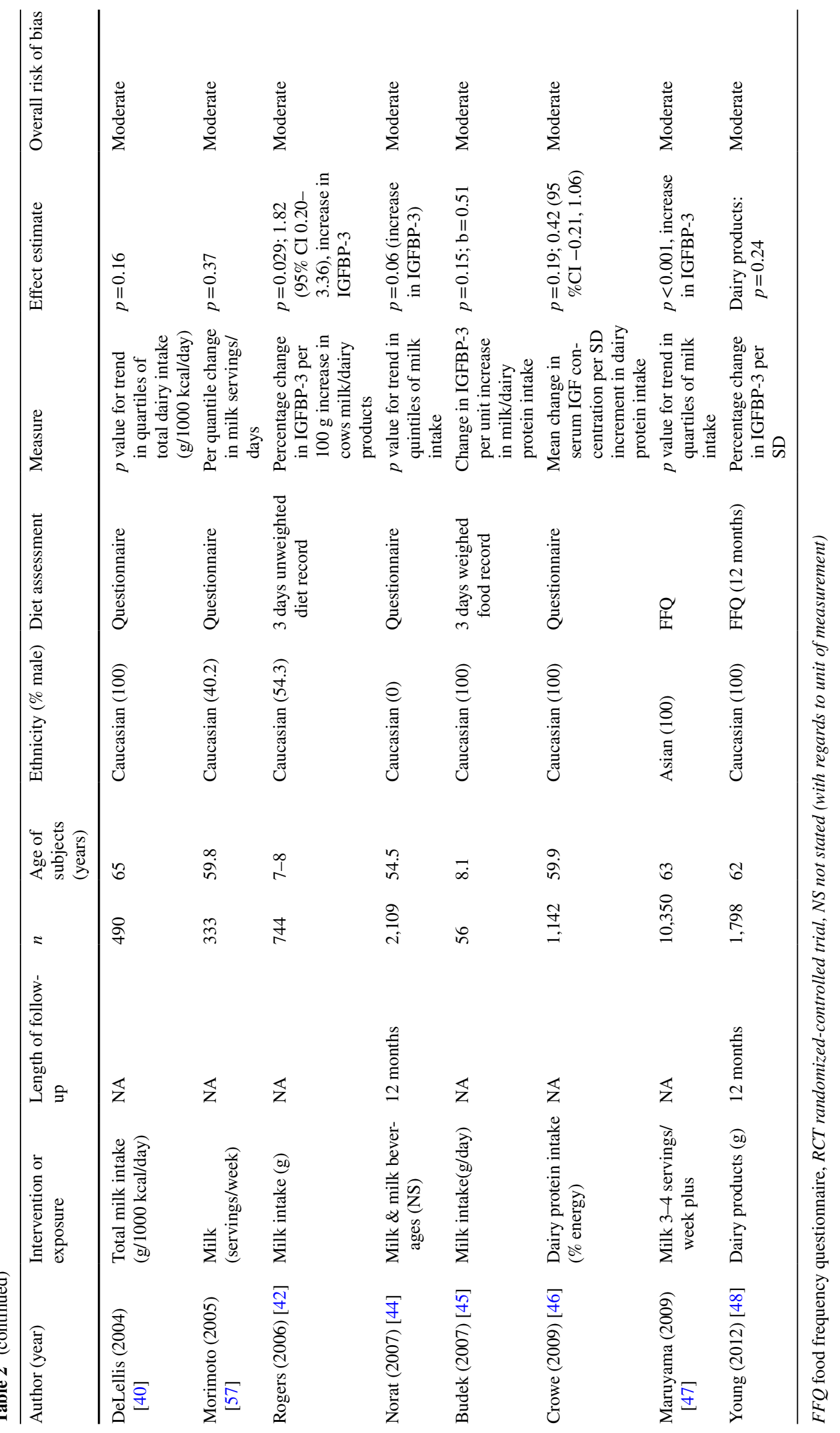




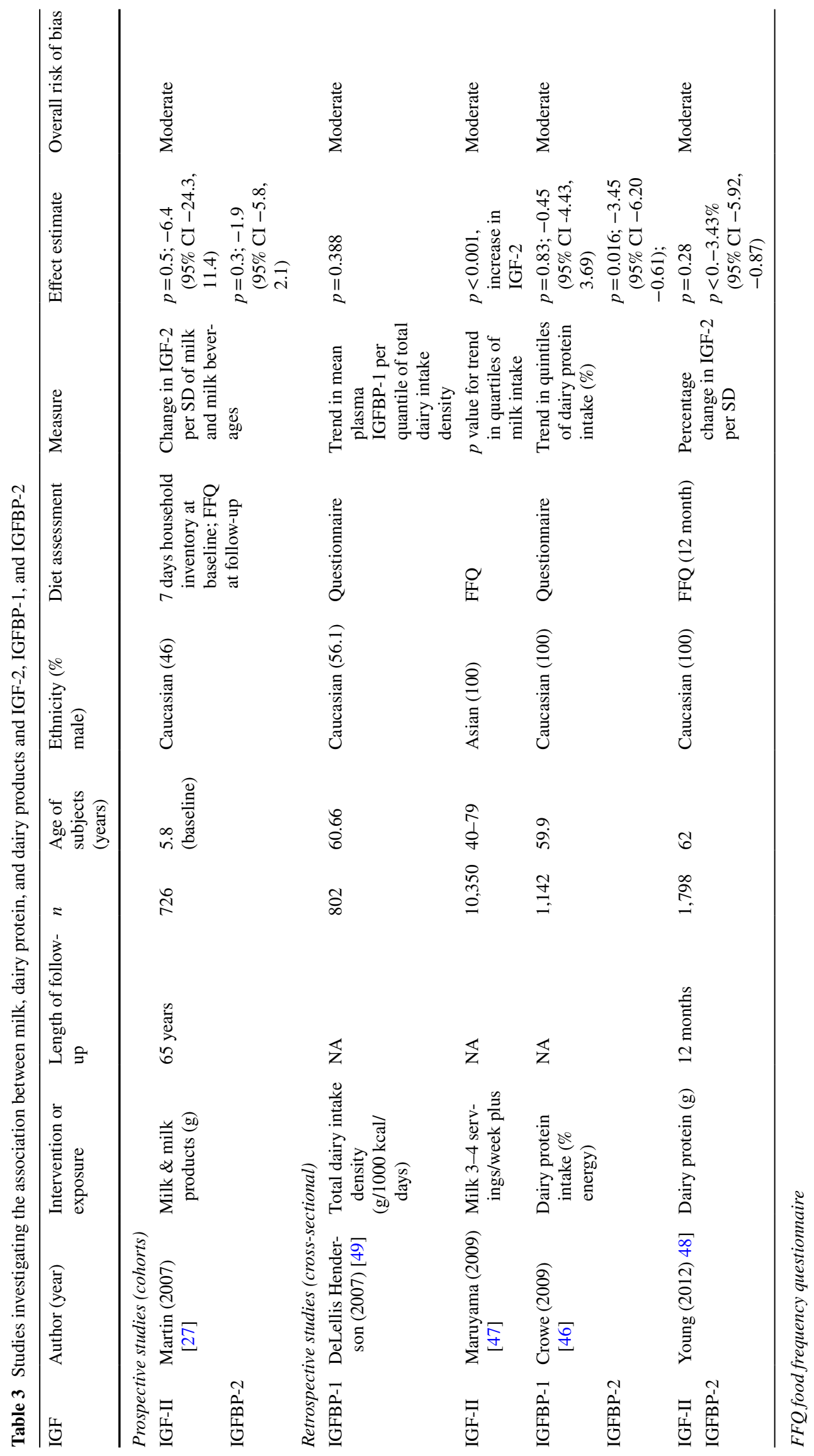


Table 4 Results for all milk-IGF associations, including subgroup analyses

\begin{tabular}{llll}
\hline Outcome & $\mathrm{N}_{\mathrm{s}}$ & $\mathrm{N}_{\mathrm{p}}$ & $\begin{array}{l}\text { Effect estimate and } \\
\text { range (from Albatross } \\
\text { plots) }\end{array}$ \\
\hline All & & & \\
IGF-I & 28 & 27,408 & $0.10(0.05-0.25)$ \\
IGF-II & 2 & 12,148 & $<0.05(0.00-0.05)$ \\
IGFBP-1 & 2 & 1,944 & $0.00(\mathrm{NA})$ \\
IGFBP-2 & 2 & 2,940 & $(-0.10$ to -0.05$)$ \\
IGFBP-3 & 15 & 24,744 & $0.05(0.00-0.10)$ \\
Caucasian only & & & $0.10(0.05-0.25)$ \\
IGF-I & 26 & 15,852 & $0.05(0.00-0.10)$ \\
IGFBP-3 & 14 & 13,935 & \\
\hline
\end{tabular}

$N_{s}$ number of studies within each analysis, $N_{p}$ number of participants across all studies

baseline milk intake, were given milk supplements; IGF-I and IGFBP-3 levels were compared before and after the supplementation. At the end of the month, mean IGF-I levels rose from $290.93 \mathrm{ng} / \mathrm{ml}$ (SD $93.98 \mathrm{ng} / \mathrm{ml}$ ) to $358.34 \mathrm{ng} /$ $\mathrm{ml}$ (SD $125.62 \mathrm{ng} / \mathrm{ml})$, an increase of $23 \%(p<0.0001)$. As no study deprived the participants of milk/dairy, this study is the best estimate of the difference in IGF-I levels between very little and some milk intake, although the small number of children limit our ability to draw firm conclusions.

A large effect was also seen in the Hoppe study [53], where 248 -year-old children were placed in two equally sized groups; the first group was asked to drink 1.51 of skimmed milk per day, the second to eat $250 \mathrm{~g}$ of low-fat meat per day, with the remaining diet up to choice. Over 7 days, the IGF-I level of the milk-group children rose from $209.3 \mathrm{ng} / \mathrm{ml}$ (SD $54.9 \mathrm{ng} / \mathrm{ml}$ ) to $249.0 \mathrm{ng} / \mathrm{ml}$ (SD $66.8 \mathrm{ng} /$ $\mathrm{ml})$, an increase of $19 \%(p<0.001)$, while the IGF-I level of the meat-group children did not change. Although both these studies were conducted in small numbers of children, they both show that large increases in milk intake can increase IGF-I levels over a short period of time.

The Cadogan and Zhu RCTs [50, 52] both supplemented the diet of children with milk, with a longer follow-up of between 18 and 24 months, and both showed that milk increases IGF-I over longer periods, albeit with a smaller effect size. The Heaney RCT [51] showed that a 12-week milk supplement in older people (mean 65 years) also increased IGF-I levels. Prospective cohort and retrospective studies in general showed a null or positive effect, consistent with but generally weaker than the RCTs and non-randomized experimental studies. For cross-sectional studies, there appeared to be little difference between studies of children and adults.
The two negative associations seen in the Ben-Shlomo and Martin studies were relatively strong, with $p$ values of 0.01 and 0.06 , respectively, and estimated effect sizes of between 0.05 and 0.10 SDs [27, 28]. These studies were not included in the main analysis of IGF-I, as the studies had a qualitatively different follow-up period, where the exposure (in childhood) was far removed in time from the outcome (in adulthood). This is a different research question, possibly looking at programming of the IGF-I axis rather than a direct effect of milk intake on IGF levels [196].

In the Ben-Shlomo study, pregnant mothers were randomized during 1972-1974 to either receive vouchers for free milk until the child reached 5 years of age, or to receive no vouchers, with the serum IGF levels measured in offspring at a mean age of 50 years. In the Martin paper, diets and physical health surveys were given to children aged between 0 and 19 years (mean age 7 years) in 1937-1939, and these children were traced and invited to follow-up in 2002-2003, when IGF levels were measured.

\section{The association between milk and IGFBP-3}

In total, 15 studies presented data for IGFBP-3, one of which reported data for two ethnic subgroups. All studies showed a positive association between milk intake and IGFBP-3 levels. The estimated standardized effect size was 0.05 SD increase in IGFBP3 per 1 SD increase in milk (estimated range 0.00 to $0.10 \mathrm{SD}$, Fig. 3b). The combined $p$ value was $4.3 \times 10^{-15}$. Similar to IGF-I, the three studies that had the largest effect estimates and smallest $P$ values used milk as an exposure rather than dairy products or protein $[36,45,53]$. There were few non-Caucasian studies looking at IGFBP-3, therefore the estimate for Caucasians only did not change.

Among studies that had examined the effect of milk on IGFBP-3, the 16 data points (from 16 studies) all had a positive effect size, centered on an effect size of about 0.05 SD. Almost all milk-IGFBP-3 studies were prospective cohorts or cross-sectional studies with reasonably similar effect sizes, regardless of age or ethnicity. Hoppe studied both IGF-I and IGFBP-3, and found a positive association (smaller than for IGF-I) with a 5\% increase in IGFBP-3 in the milk-group children $(p<0.05)$ [53].

Ben-Shlomo and Martin studied IGFBP-3 as well as IGF-I [27, 28]; as with IGF-I, these studies were not included in the albatross plot due to differences in study design. Both studies found very slightly negative associations ( $p=0.55, p=0.5$, respectively), in contrast to the other studies that all found positive associations. 

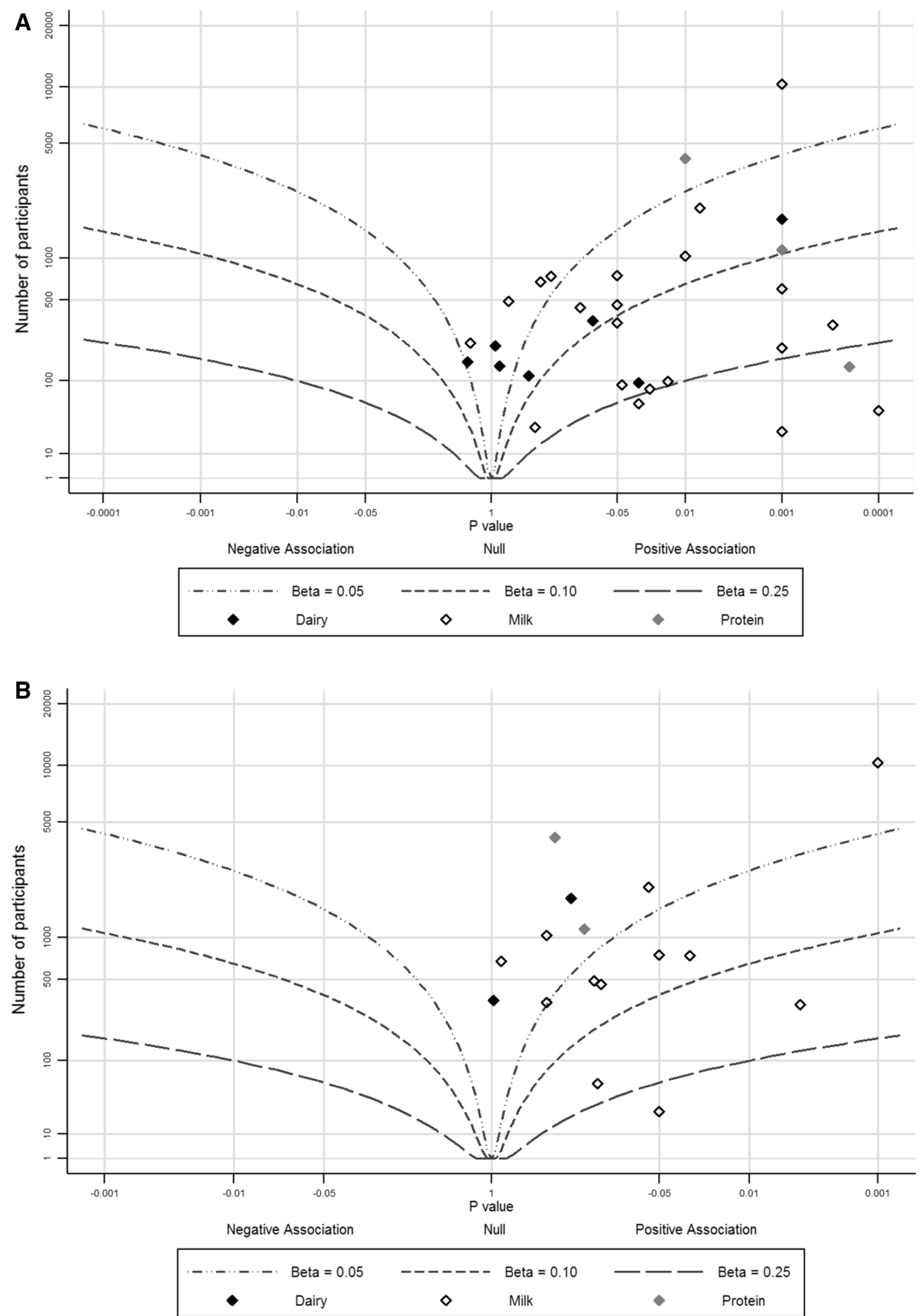

Fig. 3 Albatross plots for each outcome: a IGF-I and b IGFBP-3, stratified by exposure. Each point represents a single study included in the meta-analysis, with the effect estimate (represented as a $p$ value), plotted against the number of subjects included within each study. Effect estimates are standardized beta coefficients. Where $p$ values were presented as $<0.05$, they were plotted as 0.05 as a conservative estimate 


\section{The association between milk and other IGF proteins}

Two studies examined the association between milk/ dairy protein intake and IGF-II levels; a large study of milk intake in elderly Japanese men $(p=0.001)$ [47] and a smaller study of dairy protein intake in Caucasian men $(p=0.28)$ [48]. The studies showed a very weak positive association between milk and dairy protein intake and IGFII levels (effect estimate: $<0.05$ SDs, range 0.00-0.05 SDs, Supplementary Fig. 1A); the combined $p$ value was 0.001 .

There was no suggestion of an association between milk, dairy product or dairy protein intake and serum levels of IGFBP-1 (effect estimate: $0.00 \mathrm{SD}$, no range, Supplementary Fig. 1B), as the two included studies had $p$ values of 0.39 and 0.83 , respectively, and effect estimates in opposite directions $[46,49]$. The combined $\mathrm{P}$ value was 0.32 .

The two studies which examined the association between milk/dairy protein and IGFBP-2 levels both suggested that intake of dairy products and dairy protein led to a small decrease in serum levels of IGFBP-2 (effect estimate between -0.10 and -0.05 SDs Supplementary Fig. 1C); the combined $p$ value was 0.00021 .

The Martin study [27] also examined IGF-II and IGFBP2 , which both showed a slight negative association with $p$ values of 0.5 and 0.3 , respectively.

\section{IGF-Prostate Cancer: human studies}

\section{Circulatory levels of IGF and Prostate Cancer risk}

In total, 59 studies were included in this meta-analysis, consisting of 18 prospective and 41 retrospective studies. Nine studies had not been included in the Rowlands 2012 paper [129, 133, 134, 142, 147, 148, 152-154] and eight studies that were included in the Rowlands 2012 analysis were excluded due to critical RoB [175-178, 180-183]. Data were extracted for all five IGF and IGFBP peptides. All results presented are from random effects meta-analysis, with fixed effect results commented on if necessary.

OR values $(95 \% \mathrm{CI})$ per SD of exposure increase for retrospective and prospective values combined were as follows (Table 5): IGF-I, $n$ studies $=51$, OR $1.09(95 \%$ CI 1.03, 1.16) (Fig. 4); IGF-II, $n=10$, OR 1.07 (0.97, 1.18); IGFBP-1, $n=4$, OR 1.02 (0.77, 1.34); IGFBP-2, $n=6$, OR $1.07(0.91,1.25)$; and IGFBP- $3, n=39$, OR $0.90(0.83,0.98)$ (Fig. 5). Overall, there was a moderateto-high degree of inconsistency across the studies for all five IGF and IGFBP peptides ( $\mathrm{I}^{2}$ 66-88\%; Supplementary Fig. 2) and the inconsistency within the retrospective data was consistently greater compared to prospective studies. Due to extreme outliers, the fixed effects metaanalysis result for IGFBP-3 shows a very small positive association with $\mathrm{PCa}$ risk, whereas the random effects result shows a small negative association (fixed OR 1.02 $[1.00,1.04]$; random OR 0.90 [0.83, 0.98]).

Correspondingly, there was some evidence of small study effects in IGFBP-3 studies, possibly indicating publication bias; Egger's test $p=0.02$, with funnel plots showing that retrospective studies were responsible for a greater degree of heterogeneity and more extreme effects (Supplementary Fig. 3). IGF-I studies also showed retrospective studies to be more inconsistent, but Egger's test showed no evidence of small study effects, $p=0.44$. No other exposures showed signs of publication bias or small study effects in either funnel plots or Egger's tests. There was no association between sample size and OR when performing meta-regression on prospective IGF-I $(p=0.68)$ or IGFBP-3 $(p=0.99)$ studies.

\section{Subgroup analyses}

Advanced prostate cancer risk Data for advanced PCa risk and IGF-I and IGFBP-3 were presented in 12 studies each. OR values $(95 \% \mathrm{CI})$ per standard deviation of exposure increase for retrospective and prospective studies combined were as follows: IGF-I, $n=12$, OR $1.04(0.94,1.14)$ and IGFBP-3, $n=12$, OR $0.95(0.87,1.03)$ (Supplementary Fig. 4). Egger's test and funnel plots showed small study effects and publication bias for IGFBP-3 $(p=0.006)$, but not IGF-I $(p=0.55)$. The estimates for advanced PCa risk and all PCa risk were not materially different for either IGF-I or IGFBP-3 ( $p=0.41$ and $p=0.37$, respectively).

Retrospective versus prospective studies Inconsistency was much greater among retrospective studies compared to prospective studies across all subgroup analyses and overall. OR values were consistently higher in all retrospective analyses for all five IGF or IGFBP peptides, with the exception of IGFBP-3, which was slightly lower (for IGFBP-3: retrospective OR 0.84 [0.71, 0.99]; prospective OR $1.02(0.99,1.05) ; p=0.01$ for difference between prospective and retrospective studies) (see Table 5).

PSA screened versus clinically detected In total, there were far fewer studies that used PSA screening to detect cases $(n=6)$ compared to those where cases were identified clinically $(n=59)$. Overall, there was no discernible trend in the effect of PCa detection methods on IGF levels and PCa risk (Table 5). The only distinct difference in OR values between these two subgroups was in IGFBP-3, where the PSA-detected PCa OR was $1.06(0.94,1.19)$, higher than the clinically detected PCa OR of $0.87(0.79$, $0.97), p=0.02$. 


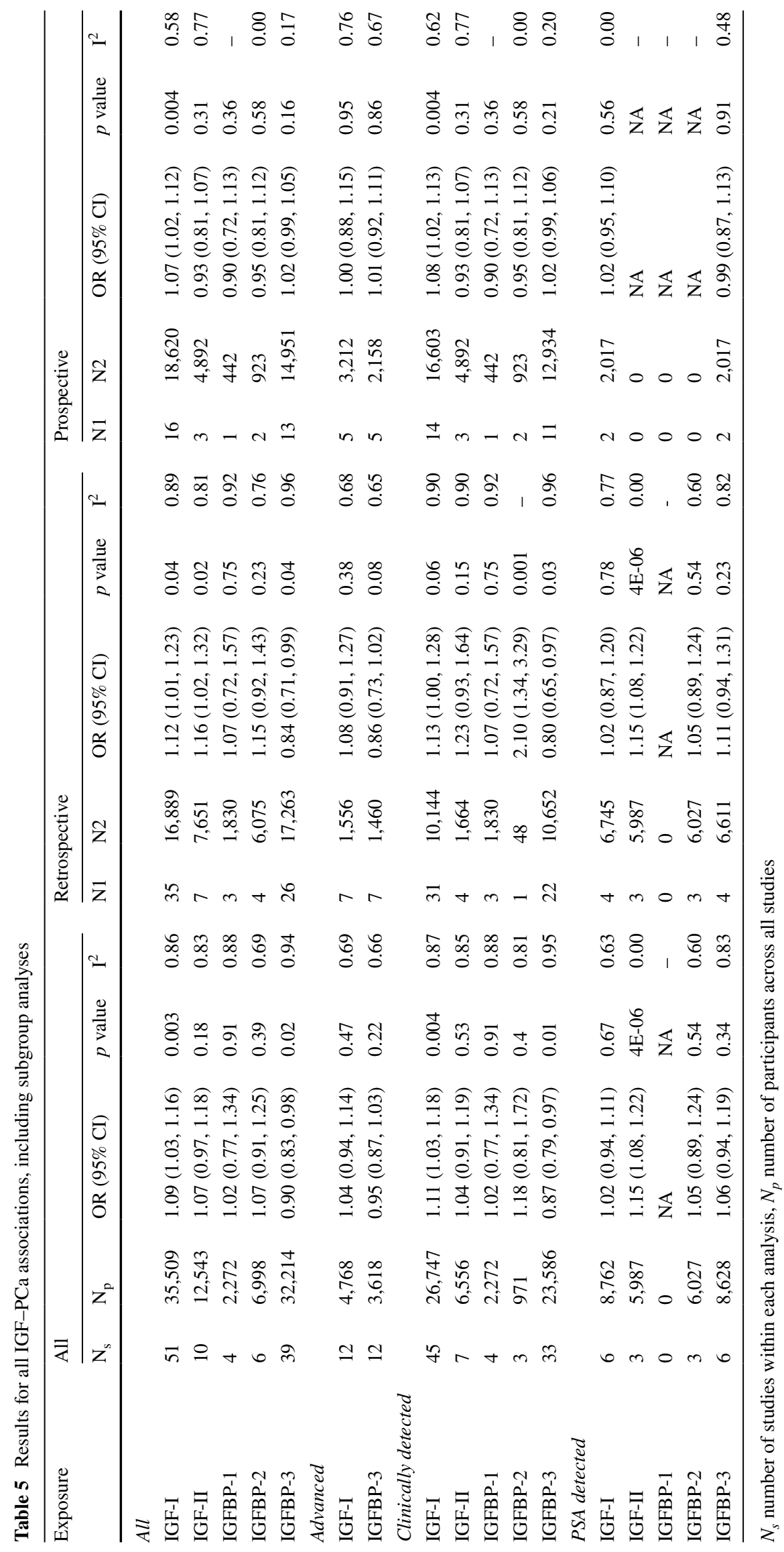




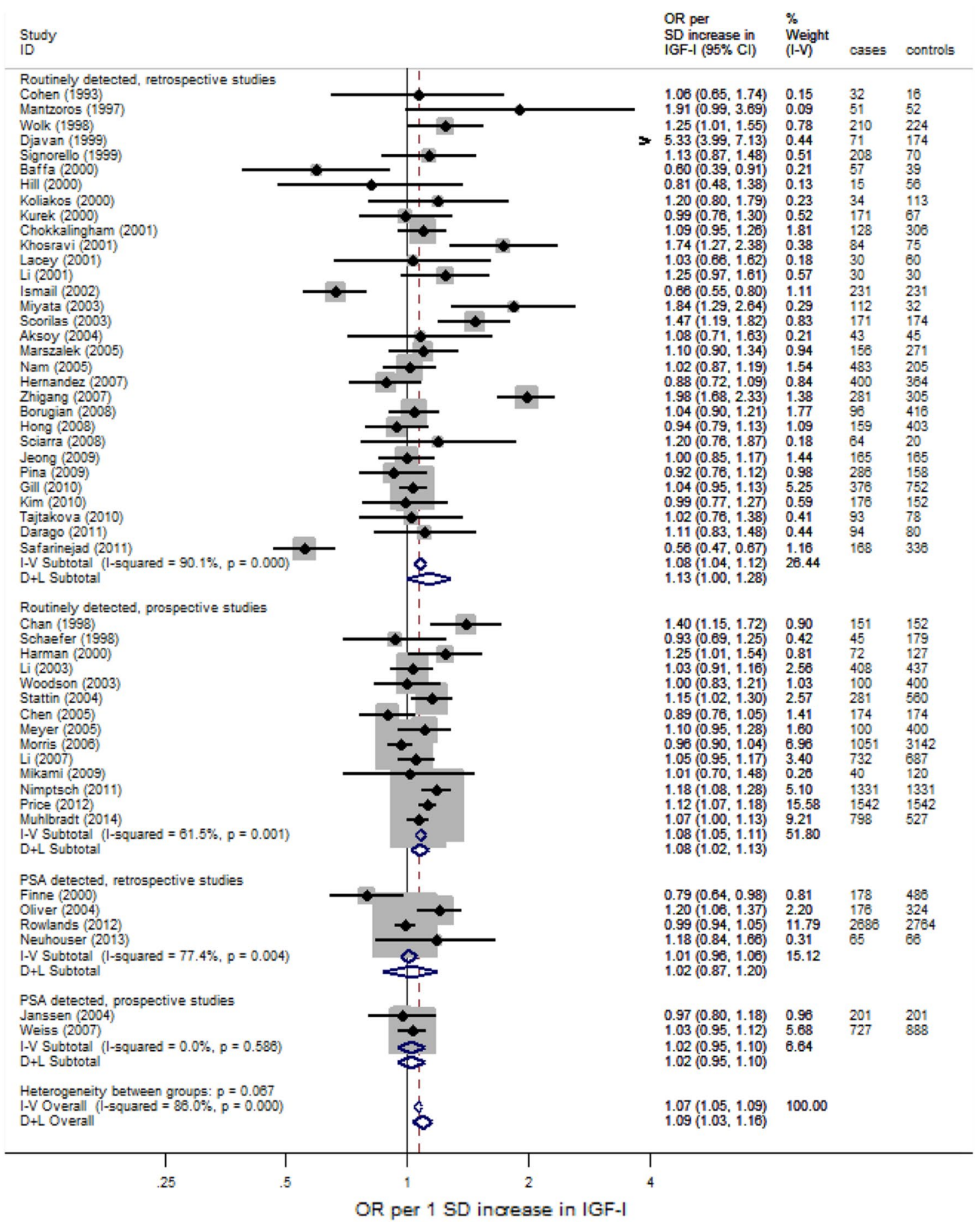

Fig. 4 Forest plot for all studies that presented data on circulatory levels of IGF-I in relation to PCa risk, stratified by study design (prospective vs retrospective) and PSA-detected PCa cases

\section{Genetic data}

In total, 18 studies presented data relevant to genes or SNPs within the IGF pathway, in relation to PCa risk. Of these, data for only two polymorphisms: IGF-I (CA) $\mathrm{n}$ repeat and IGFBP-3 SNP-202A/C, were presented in three or more studies, allowing for meta-analyses. Another 46 SNPs or genes were identified in the review; however, only one set of data was available for 42 of the SNPs and two sets of data for four of the SNPs 


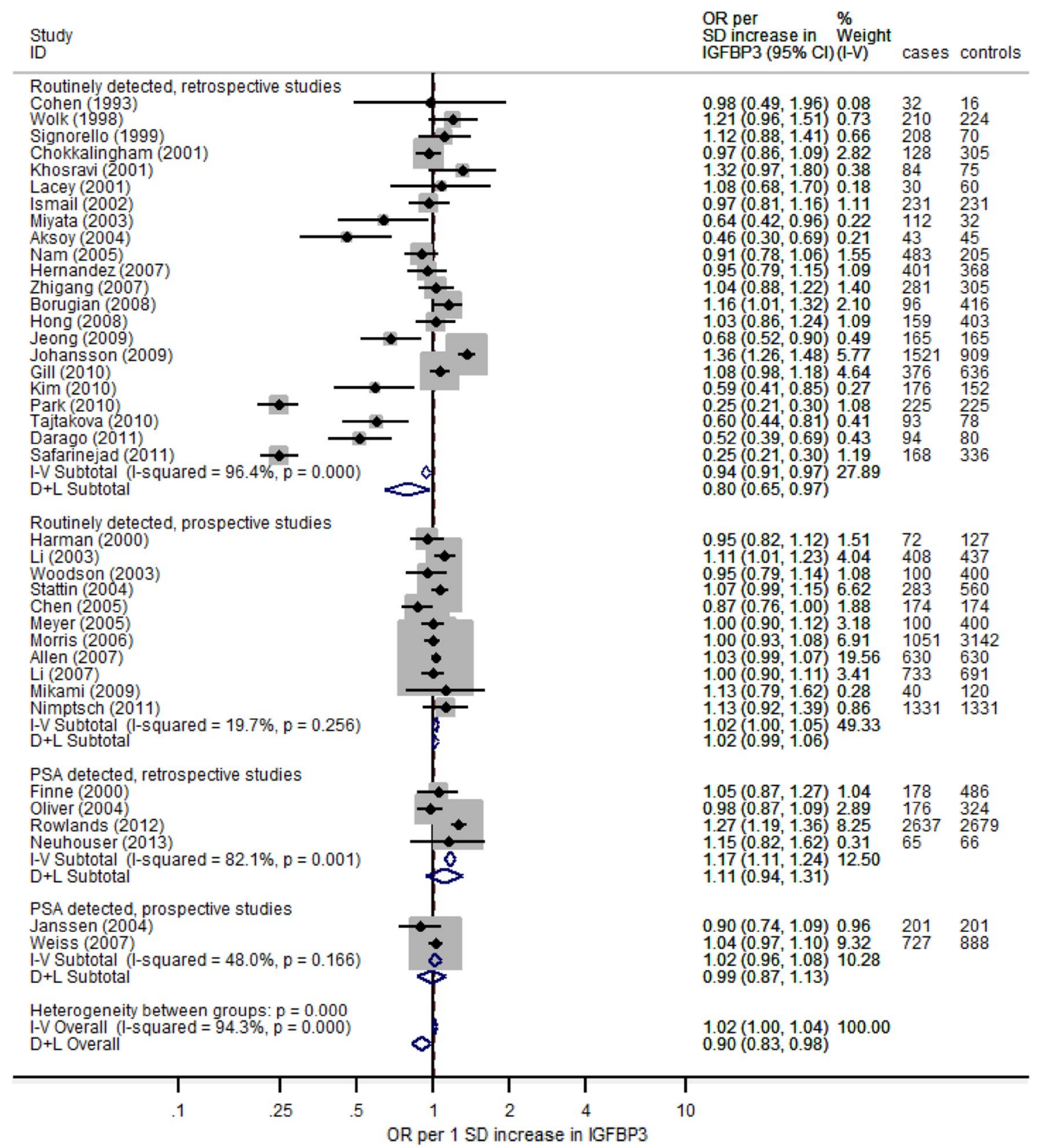

Fig. 5 Forest plot for all studies that presented data on circulatory levels of IGFBP-3 in relation to PCa risk, stratified by study design (prospective vs retrospective) and PSA-detected PCa cases

(Supplementary Table 2). Again, all results presented are from random effects meta-analysis.

OR values $(95 \% \mathrm{CI})$ for the two meta-analysable polymorphisms, were as follows: IGF-I (CA)n ( $n=5$ studies) when compared against a 19/19 repeat, where $\mathrm{X}$ is anything other than 19, the X/X repeat had an OR $0.98(0.56,1.73)$, and $X / 19$ repeat had an OR $0.99(0.63,1.55)$. For IGFBP3-202A/C SNP ( $n=8$ studies), when compared against the $\mathrm{A} / \mathrm{A}$ allele, the $\mathrm{A} / \mathrm{C}$ allele had an OR $1.22(0.84,1.79)$, and the $\mathrm{C} / \mathrm{C}$ allele had an OR $1.51(1.03,2.21)$ (Supplementary Fig. 5).

\section{IGF-prostate cancer: animal models}

Of the 10 animal studies included in the analysis (Table 6), eight provided data on mechanistic IGF pathways, in relation to PCa risk or progression. Four of these studies were transgenic mice models, which over-expressed [186] or 


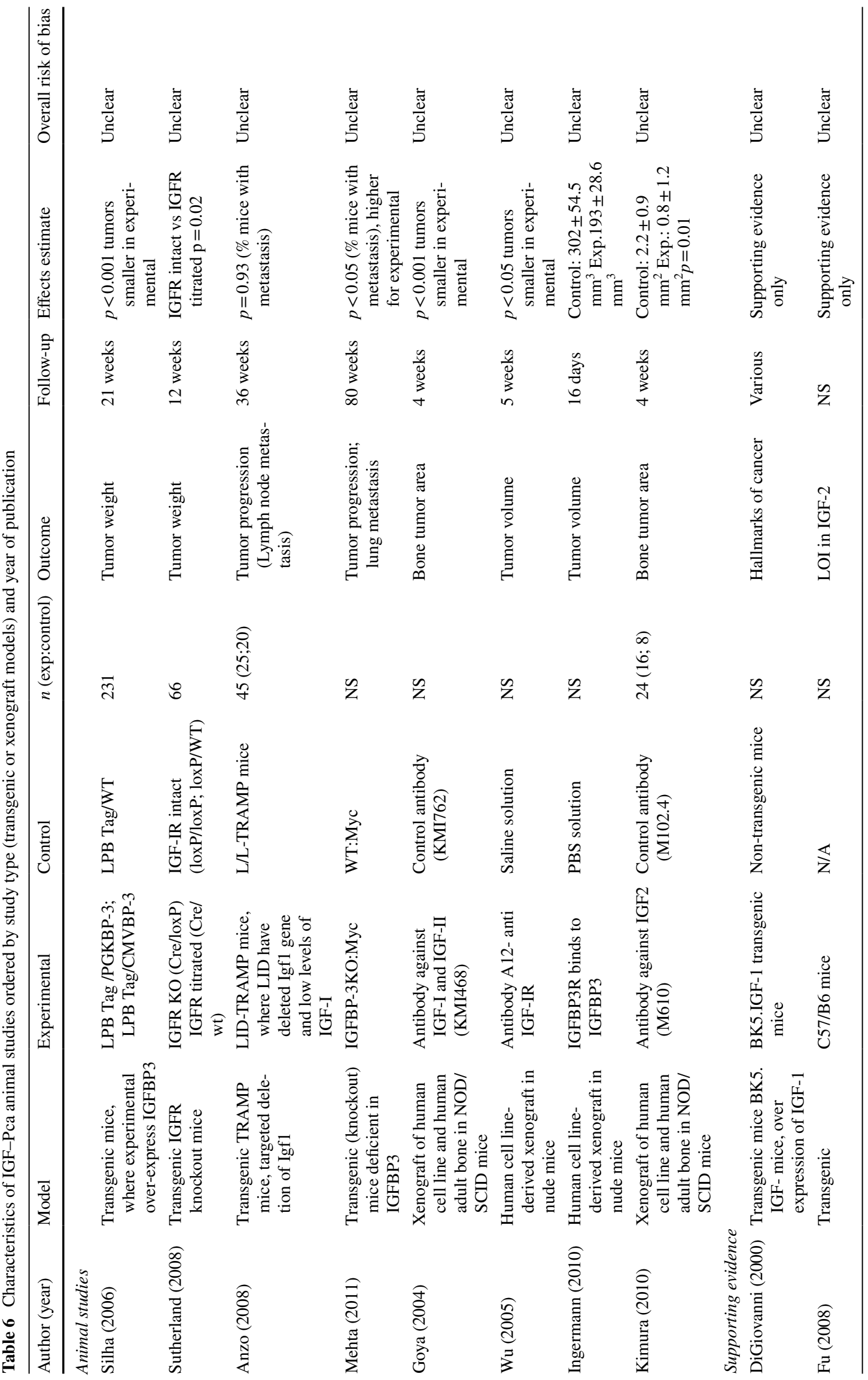


knocked-out IGFBP-3 [189], or knocked-out IGF-IR [187] or $I G F-I$ [188]. The remaining four studies were xenograft models that used antibodies to bind to IGF peptides [190, 193] or IGF-IR [191] or IGFBP-3 [192].

Seven out of the eight studies found statistically significant differences between experimental and control models, with a small level of consistency between results (Table 6). Two studies found a positive association between tumor progression and IGFBP-3 suppression or deficiency [189, 192], while another found tumor size to be smaller within mice that over-expressed IGFBP-3 [186]. In addition, both studies that provided data on IGF-II found that IGF-II suppressed mice had significantly smaller tumors [190, 193]. Two studies had contradictory results with regards to IGF receptors (IGF-IR), in that deleted IGF-IR accelerated the emergence of aggressive $\mathrm{PCa}$ in one experimental model [187], while in another tumors were smaller in IGF-IR suppressed mice [191].

One animal study investigated the association between loss of imprinting in IGF-II and PCa susceptibility [195]. The paper was a short communication and did not provide enough data to be included in the main analysis; however, it was included as supporting evidence. The remaining studies presented only data on the hallmarks of cancer as outcomes and were therefore also included only in supporting evidence [194].

\section{Supporting evidence}

In total, 49 studies were included within the supporting evidence category; 16 of these studies investigated the association between circulating levels of IGF-I $(n=14)$, IGF-II $(n=2)$, IGFBP-2 $(n=2)$ or IGFBP-3 $(n=8)$ with prostate cancer risk or prostate cancer outcomes such as Gleason grade, TNM stage or PSA-progression free survival. 18 studies investigated the association between tissue expression of IGF-I $(n=5)$, IGF-II $(n=4)$, IGF-IR $(n=7)$, IGFBP-2 $(n=7)$, IGFBP-3 $(n=6)$ with risk of prostate cancer or prostate cancer outcomes such as Gleason Grade or TNM stage. Fifteen studies investigated whether genetic or epigenetic variations in the IGF-I $(n=5), I G F-I I(n=7)$, $\operatorname{IGFBP}-2(n=2)$ or IGFBP-3 $(n=3)$ gene were associated with prostate cancer risk or outcomes such as Gleason score, TNM stage, PSA recurrence or survival. Results from individual studies were generally not consistent with each other, and therefore did not influence our overall conclusions. The results are presented in Supplementary Tables 3, 4 and 5 .

\section{Risk of bias and GRADE}

Generally there was a moderate RoB across the majority of study types, with the exception of animal models where the overall RoB was 'unclear' due to the lack of information provided within the papers to inform a number of the RoB subcategories. Only 11 human observational studies were classed as having critical RoB, and therefore excluded from the metaanalysis on this basis. All but one of the human RCTs in the Milk-IGF analysis were given an 'unclear' RoB rating, due to the lack of data to inform particular RoB sub-categories.

The overall GRADE assessments found that there was moderate evidence from human studies that milk intake increased IGF-I levels and there is low-level evidence that milk reduces IGFBP-3 levels. We also found moderate evidence from human studies that increasing IGF-I levels increases prostate cancer and advanced prostate cancer risk, and low-level evidence of no effect of IGFBP-3 levels on prostate cancer and advanced prostate cancer risk. It should be noted that although the evidence for an association between IGF-I and prostate cancer was strong, observational studies cannot by themselves offer strong evidence for causal associations; therefore there is only moderate evidence that IGF-I levels increases prostate cancer risk. For associations between all other IGF biomarkers, there was very low-level evidence of any effect. Common reasons for downgrading were imprecision (especially for IGF biomarkers which had a small number of studies) and publication bias. For full details on GRADE assessments, see Supplementary Tables 6, 7, 8, $9,10,11,12,13,14,15,16,17$, and 18 .

The animal studies were collectively found to offer very low-level evidence that the IGF pathway was related to prostate cancer risk. The reasons for this are as follows: (1) although they were all experimental studies, they had unclear risk of bias due to a lack of information on key variables; (2) we were unable to look at consistency across studies as each study was very different from the other; (3) we downgraded animal studies for indirectness because in the animal studies, components of the IGF pathway were over-expressed to very high levels or knocked out which does not reflect variation within the normal range in humans. In addition, animal studies measured outcomes in terms of tumor weight or volume rather than incidence; the level of imprecision was generally high due to the small number of animals in each experiment and the inability to combine across very different studies. Finally we felt that there was likely to be substantial publication bias. It should be noted, however, that GRADE assessments were designed for use in human studies rather than animal studies.

\section{Discussion}

\section{Milk-IGF}

Based on the overall synthesis of data, there was moderate evidence to suggest that milk intake was positively 
associated with increased levels of IGF-I and IGFBP-3. This trend appeared to be greater in studies that consisted of non-Caucasian subjects, particularly in IGF-I, and supports results from previous studies that demonstrate that ethnicity can be a contributing factor to increased levels of circulating IGF. It is not possible in this review to elucidate whether ethnicity or differences in normal milk intake have caused these differences. However, although there may be a true difference between ethnicities, it is more likely that lower milk intake in non-Caucasian ethnicities causes larger effects of milk on IGFs, both in experiments where milk is added to the diet and in observational studies where the range of milk intake is much larger.

Across both analyses for IGF-I and IGFBP-3, the largest effect on IGF levels was seen when milk was used as an exposure, rather than dairy protein or its products. Studies in the IGFBP-3 analysis, that used dairy protein or products as exposures, were not seen to contribute to the overall positive association; rather this association was observed only in those studies that used milk as a standalone exposure. Although the original search terms for this analysis were designed to include dairy protein and products as additional exposures, to ensure a broad coverage of exposure types that could include milk, the overall results suggest that 'diluted' exposure categories may not be as pertinent in elucidating the true association between milk and IGF levels.

The analysis of IGFBP-2 in this arm of the study consisted of only two studies, both of which classified the exposures as dairy protein and products. Despite the small number of studies and 'diluted' exposure types, the analysis produced weak evidence to suggest that IGFBP-2 levels decrease with these types of exposures. Speculatively, further studies using milk alone as an exposure may be useful to ascertain whether there is a stronger negative association between IGFBP-2 and milk intake, compared to the results in this analysis that may be under-powered. Additionally, a similar observation can be made for the weak positive association that was found between IGF-II and milk and dairy protein, as only two studies provided data for this protein.

IGFBP-1 was the only protein to produce a null association with milk and dairy proteins and products; however, there were only two studies available for this analysis, both of which used dairy product or protein as an exposure. Overall, the analyses of the small number of studies available for IGF-II, IGFBP-1, and IGFBP-2 present a more conservative estimate of the effect of milk on levels of these proteins and warrant further data to confirm the presence or absence of any associations.

Overall there was a large amount of data for the milk-IGF analysis, however, there was considerable inconsistency within study design that made it difficult to assimilate the results in such a way to produce a statistic that would represent the associations present across all the studies as a whole. As part of the analysis, we were able to account for ethnicity by differentiating these sets of data within the albatross plots, but other aspects of study design were more difficult to account for. One of the main divisions between study types were those that followed up interventions over weeks or months and those that followed interventions up after a number of years; essentially providing data for short-term and long-term consequences of milk interventions. Studies with a different study design, which looked at milk exposure in childhood and IGF levels in adulthood, were considered separately as these may reflect a programming effect, rather than a direct effect.

One possibility for the apparent shift from a positive association between milk and IGF-I in the short term to a negative association in the long term is programming of the IGF axis in childhood [196]. The theory developed in this study is that high milk consumption in childhood increases IGF-I in the short term; this leads to feedback and programming of the IGF axis, which modulates the amount of IGF-I in the body, leading to a reduced amount of IGF-I in adulthood.

\section{IGF-Prostate cancer}

The results from our IGF-PCa analysis reflect those from the previous meta-analysis [8]; however, the strength of the associations seen in the current paper appears to be smaller; OR values for all IGF proteins in this study were between 0.90 (IGFBP-3) and 1.09 (IGF-I), compared to between 0.88 (IGFBP-3) and 1.21 (IGF-I) in the earlier Rowlands study [7]. However, the directions of effect for all IGF proteins were consistent between this study and Rowlands, and all results had $p$ values above 0.05 when testing for differences between estimates [20], there is therefore no evidence to suggest that the results were inconsistent. The standard errors of the current study's estimates were all lower than in the Rowlands study, indicating greater precision.

These differences in estimates and precision may in part be due to more rigorous risk of bias protocols, which have ensured that the quality of the data presented here is high and that confounding factors (with particular focus on age) have been accounted for. Eight papers, consisting of $941 \mathrm{PCa}$ cases, were included in the Rowlands analysis and were excluded in this study due to age not being considered in the design or analysis of the studies. This may account for some of the differences between the results between the current versus the earlier Rowlands study [8]. The addition of studies published after 2012 may have also affected the results. Additionally, an evaluation of meta-analyses of biomarker associations with cancer risk [197] concluded that there may be bias present specifically in the metaanalyses of IGF with cancer risk, of which the Rowlands 
meta-analysis was one; by removing studies with the highest risk of bias, it is possible some bias has been removed. This study thus provides a refined and updated assessment of the previous IGF-PCa association.

Both the current study and the Rowlands study, showed a marked difference between the quality of retrospective and prospective studies, both in terms of heterogeneity and possible publication bias; retrospective studies in general had a larger amount of inconsistency and displayed more non-symmetry in funnel plots. All eight studies excluded from this study, but included in Rowlands, were retrospective; this may have contributed to the relative imprecision of the Rowlands results, as well as making those results more extreme.

In our current study, there were few differences between the results from studies with clinically detected vs PSAdetected PCa (Table 5); while there may simply be few differences between IGF and PSA or clinically detected $\mathrm{PCa}$, it is more likely that the lack of difference is due to the difficulty in ascertaining the method by which the PCa cases are found and recruited, and may reflect the ubiquity of the screening for PCa using the PSA in the general population. As PSA testing has become the normal method of testing for prostate cancer in the USA and many other countries worldwide, prostate cancer cases are being found earlier and with more indolent disease. Thus, newer studies likely have a different case-mix to earlier studies, with a greater proportion of early and indolent cancers. If IGF action on prostate cancer affects progression as well as (or as opposed to) incidence, then the overall effect estimate of IGF on prostate cancer will be reduced by a change in case-mix favoring indolent cancers. It is possible that some of the differences between this study and the Rowlands study were as a result of changing the case-mix by excluding older studies, which may have had more clinical cases, (with critical risk of bias) and including newer studies, which may have had more PSA-detected cases. However, this is balanced by our finding showing that advanced prostate cancer risk was no more associated with IGF-I and IGFBP-3 than prostate cancer risk as a whole; if IGF was associated with progression, it would likely be seen when examining advanced prostate cancer risk. However, advanced prostate cancer was defined differently between studies and may not be representative of cancers that have "progressed," especially as the advanced cancers may have been found earlier through PSA testing.

Within the genetic portion of the IGF-PCa analysis, the C/C genotype of the IGFBP-3 SNP-202A/C, presented a strong, positive association with PCa risk (OR 1.51), alongside a moderate association with the $\mathrm{A} / \mathrm{C}$ genotype of the same SNP (OR 1.22). This genotype is associated with a higher IGF-I level relative to the A/A genotype [198], and therefore the finding supports the hypothesis that IGF-I is positively associated with PCa risk. Repeats of (CA) did not provide evidence for any association between IGF-I and PCa risk, but only 5 studies were included, which had very inconsistent results; Schildkraut [170] estimated an odds ratio of 3.33 (1.26-8.82) for $19 / 19$ repeats against non-19/non-19 repeats, whereas Tsuchiya [165] estimated an odds ratio of $0.30(0.12-0.77)$. This may be due to differences in study populations: Schildkraut recruited men in the USA, with a prevalence of $27 \%$ for the $19 / 19$ allele; Tsuchiya recruited men in Japan, with a prevalence of only $6 \%$ for the $19 / 19$ allele.

Although a larger number of studies provided data that was eligible for the genetic analysis, only two alleles had enough data to be meta-analyzed. Overall, there is a distinct lack of data with regards to many other genes and SNPs within the IGF pathway, with the majority of SNPs only being studied within one population within one study.

A recent Mendelian randomization study of the IGF pathway and prostate cancer [199] concluded that the IGF pathway may be associated with prostate cancer, but because of the potential for pleiotropy, no individual IGF protein could be identified as having a specific association.

When we subjected the evidence to GRADE assessments, we found that at best there was moderate evidence of an association for milk-IGF-I and milk-IGFBP-3, but for the most part, the evidence was of a low or very low level. GRADE takes into account the totality of evidence to determine the overall strength of a reported association and the potential for it to have been influenced by bias. As most of the evidence on both milk and the IGF pathway, and the IGF pathway and prostate cancer was observational, there is a great deal of potential for bias to have occurred. In addition for some biomarkers (IGF-II, IGFBP-1 and IGFBP-2), the small number of studies carried out meant that the level of imprecision was high. These results indicate that even for the IGF-I-prostate cancer association where many studies have previously been focused, the evidence that IGF-I increases prostate cancer risk is not strong, and there is a need for further high-quality studies that are free from bias to address this question. To our knowledge, GRADE has not previously been applied to animal studies in this way, the main reasons why these studies scored so low in this assessment was the lack of information on experimental methods, the lack of similar studies to assess consistency and the potential for publication bias. As noted, however, GRADE was developed for use in human studies and may not be appropriate when considering animal studies, which have very different methodologies. Additionally, while animal studies may not be suitable for assessing the strength of the evidence underlying mechanistic pathways, they may be extremely useful in identifying and highlighting mechanisms which can then be tested in human studies. 


\section{Combining results from the milk-IGF and IGF- prostate cancer analysis}

When looking at the overall results from the milk-IGF and IGF-PCa data, IGF-I and IGFBP-3 are possible mediators of the association between milk intake and PCa. Broadly speaking, the data from this study lend support to the hypothesis that increased milk intake may increase circulating levels of IGF-I, which in turn may increase the risk of PCa.

There is also evidence to suggest that levels of circulating IGBP-3 can be increased by milk intake; however, this binding protein appears to have a protective effect against PCa risk (Fig. 5). This finding was only seen in retrospective studies; as such, it should be interpreted with appropriate caution as prospective studies are generally more robust.

These associations are mediated by key factors within both arms of the study, most importantly, length of followup across both arms, baseline intake of milk and dairy and ethnicity within the milk-IGF studies and age within the IGF-PCa studies. Within this meta-analysis, the methodology was designed to account for these factors to ensure that they did not bias the overall result. However, combining the effects from differing populations may mask stronger or weaker associations among these populations as individual entities, and therefore the results should be carefully interpreted in this respect.

Results for IGF-II, IGFBP-1, and IGFBP-2 across both arms of the study do not suggest a complete pathway to link milk intake to PCa risk via these IGFs; this is due largely to the paucity of studies examining these biomarkers, future studies may contribute to our understanding.

It should be noted that although the results support short-term milk intake being associated with IGF-I increase, long-term associations may be complicated by programming of the IGF axis. Therefore, drinking milk in childhood may not be associated with prostate cancer risk in the future, whereas drinking milk in adulthood may be; this may have a biological basis, as milk is a food evolved for neonates rather than adults.

\section{Supporting evidence and animal studies}

Animal models can provide evidence to support mechanistic pathways that connect IGF as an intermediate phenotype between milk intake and PCa risk; however, the application of these within a human-based review requires caution. The data from animal studies and results from supporting evidence studies were highly heterogeneous, encompassing a large variety of study designs, outcomes and exposures relating to IGF and PCa risk; as such, it was not possible to carry out detailed meta-analyses for these data. When
IGF-I levels were reduced by producing antibodies against IGF-I [190], tumor volume was reduced relative to controls, whereas tumor volume was higher in IGFBP-3 knockout animals [189]. These studies therefore support the associations that were found within the human IGF-PCa analysis.

When assimilating the data from all the supporting evidence studies, the results were conflicting. The studies had looked at the effect of cancer treatment on IGF levels, how IGF levels changed over time in prostate cancer patients, the association between IGF levels and precancerous lesions, the expression of IGF in prostate cancer tissue vs normal prostate and other tissue, haplotypes in IGF-I and prostate cancer risk, SNPs in the IGF pathway and cancer survival, loss of IGF-II imprinting and cancer risk, and methylation of IGF genes. These data provided evidences for positive, negative, and null associations between IGF exposures and $\mathrm{PCa}$ risk, with positive associations as the most prevalent associations.

\section{Limitations}

An important limitation of this work is that the studies examining the association between milk and IGF did not include sufficient data to perform a meta-analysis, and thus a combined effect estimate could not be calculated. However, the albatross plots allowed an approximate examination of the underlying magnitude of effect in terms of standardised mean differences, allowing conclusions to be drawn about the likely size of the association between milk and different IGFs. We acknowledge that the literature search was completed in March 2014, and therefore more recent relevant studies may have been missed. However, one particular strength of this study is the inclusion of many different data types, and the application of the Risk of Bias and GRADE tools to the data allowing for a more robust conclusion.

\section{Conclusion}

The diversity of studies created a complex meta-analysis structure, which has required strict inclusion/exclusion criteria to allow meta-analysable data across a number of study types. Overall, the combined evidence from human and animal observational, experimental, and genetic studies provides evidence to support a role of the IGF pathway, in particular IGF-I in explaining the association between milk and prostate cancer.

Acknowledgments Giota Mitrou, Martin Wiseman, Rachel Thompson from the World Cancer Research Fund (WCRF) International and Pierre Hainaut from the Institute for Advanced Biosciences, Grenoble for contributing to discussions on the methodology and results presented in this paper. 
Funding Funded by World Cancer Research Fund (grant number: RFA 2012/620). SH is a Wellcome Trust Funded PhD student with Grant code 102432/Z/13/Z. Additionally supported by funding from the MRC Integrative Epidemiology Unit at the University of Bristol (MC_UU_12013/1, MC_UU_12013/2) and a Cancer Research UK (C18281/A19169) Programme Grant (the Integrative Cancer Epidemiology Programme). RMM is supported by the National Institute for Health Research (NIHR) Bristol Nutritional Biomedical Research Unit based at University Hospitals Bristol NHS Foundation Trust and the University of Bristol.

Open Access This article is distributed under the terms of the Creative Commons Attribution 4.0 International License (http:// creativecommons.org/licenses/by/4.0/), which permits unrestricted use, distribution, and reproduction in any medium, provided you give appropriate credit to the original author(s) and the source, provide a link to the Creative Commons license, and indicate if changes were made.

\section{References}

1. World Cancer Research Fund International/American Institute for Cancer Research Continuous Update Project Report: Diet, Nutrition, Physical Activity, and Prostate Cancer, available at: [http://www.wcrf.org/sites/default/files/Prostate-Cancer-2014-Report.pdf]

2. Tate PL, Bibb R, Larcom LL (2011) Milk stimulates growth of prostate cancer cells in culture. Nutr Cancer 63(8):1361-1366

3. Gilbert R, Martin RM, Beynon R et al (2011) Associations of circulating and dietary vitamin $\mathrm{D}$ with prostate cancer risk: a systematic review and dose-response meta-analysis. Cancer Causes Control 22(3):319-340

4. Sumpter JP (1998) Xenoendocrine disrupters - environmental impacts. Toxicol Lett 103:337-342

5. Qin LQ, Wang PY, Kaneko T et al (2004) Estrogen: one of the risk factors in milk for prostate cancer. Med Hypotheses 62(1):133-142

6. Qin LQ, He K, Xu JY (2009) Milk consumption and circulating insulin-like growth factor-I level: a systematic literature review. Int J Food Sci Nutr 60:330-340

7. Rowlands MA, Gunnell D, Harris R et al (2009) Circulating insulin-like growth factor peptides and prostate cancer risk: a systematic review and meta-analysis. Int $\mathbf{J}$ Cancer 124(10):2416-2429

8. Rowlands MA, Holly JMP, Gunnell D et al (2012) Circulating insulin-like growth factors and IGF-binding proteins in PSAdetected prostate cancer: The Large Case-Control Study ProtecT. Cancer Res 72(2):503-515

9. Roddam AW, Allen NE, Appleby P et al (2008) Insulin-like growth factors, their binding proteins, and prostate cancer risk: analysis of individual patient data from 12 prospective studies. Ann Intern Med 149(7):461-488

10. Hanahan D, Weinberg RA (2011) Hallmarks of cancer: the next generation. Cell 144(5):646-674

11. Harrison S, Jones H, Martin RM et al (2017) The Albatross plot: a novel graphical tool for presenting results of diversely reported studies in a systematic review. Res Synth Methods (in press)

12. Stouffer SA, Suchman EA, DeVinney LC et al (1949) The American soldier, vol. 1, Adjustment during army life. J Consult Psychol 13(4):310-310
13. Chene G, Thompson SG (1996) Methods for summarizing the risk associations of quantitative variables in epidemiologic studies in a consistent form. Am J Epidemiol 144(6):610-621

14. Greenland S, Longnecker MP (1992) Methods for trend estimation from summarized dose-response data, with applications to metaanalysis. Am J Epidemiol 135(11):1301-1309

15. Orsini N, Bellocco R, Greenland S (2006) Generalized least squares for trend estimation of summarized dose-response data. Stata J 6(1):40-57

16. Harris RJ, Bradburn MJ, Deeks JJ et al (2008) Metan: fixedand random-effects meta-analysis. Stata J 8(1):3-28

17. Higgins JPT, Thompson SG (2002) Quantifying heterogeneity in a meta-analysis. Stat Med 21(11):1539-1558

18. Egger M, Smith GD, Schneider M et al (1997) Bias in metaanalysis detected by a simple, graphical test. $\mathrm{Br}$ Med $\mathrm{J}$ 315(7109):629-634

19. Begg CB, Mazumdar M (1994) Operating characteristics of a rank correlation test for publication bias. Biometrics 50(4):1088-1101

20. Altman DG, Bland JM (2003) Statistics Notes - Interaction revisited: the difference between two estimates. Br Med J 326(7382):219-219

21. Sterne JAC, Hernan MA, Reeves BC et al (2016) ROBINS-I: a tool for assessing risk of bias in non-randomised studies of interventions. BMJ-Br Med J 355:i4919

22. CASP Case Control Checklist [http://media.wix.com/ugd/dded8 7_63fb65dd4e0548e2bfd0a982295f839e.pdf]

23. CASP Cohort Study Checklist [http://media.wix.com/ugd/ dded87_e37a4ab637fe46a0869f9f977dacf134.pdf]

24. Guyatt GH, Oxman AD, Vist GE et al (2008) GRADE: an emerging consensus on rating quality of evidence and strength of recommendations. Br Med J 336(7650):924-926

25. Schaefer C, Friedman GD, Quesenberry Jr (1998) CP: IGF-1 and prostate cancer. Science 282:199

26. Safarinejad MR, Shafiei N, Safarinejad S (2011) Relationship of insulin-like growth factor (IGF) binding protein-3 (IGFBP3) gene polymorphism with the susceptibility to development of prostate cancer and influence on serum levels of IGF-I, and IGFBP-3. Growth Horm IGF Res 21(3):146-154

27. Martin RM, Holly JMP, Middleton N et al (2007) Childhood diet and insulin-like growth factors in adulthood: 65-year follow-up of the Boyd Orr Cohort. Eur J Clin Nutr 61(11):1281-1292

28. Ben-Shlomo Y, Holly J, McCarthy A et al (2005) Prenatal and postnatal milk supplementation and adult insulin-like growth factor I: long-term follow-up of a randomized controlled trial. Cancer Epidemiol Biomark Prev 14(5):1336-1339

29. Colangelo LA, Chin BCH, Liu K et al (2005) IGF-1, IGFBP-3, and nutritional factors in young black and white men: the CARDIA Male Hormone Study. Nutr Cancer 53(1):57-64

30. Rich-Edwards JW, Ganmaa D, Pollak MN et al (2007) Milk consumption and the prepubertal somatotropic axis. Nutr J 6:28

31. McGreevy KM, D Hoel B, Lipsitz SR et al (2007) Impact of nutrients on insulin-like growth factor-I, insulin-like growth factor binding protein-3 and their ratio in African American and white males. Public Health Nutr 10(1):97-105

32. Esterle L, Sabatier JP, Guillon-Metz F et al (2009) Milk, rather than other foods, is associated with vertebral bone mass and circulating IGF-1 in female adolescents. Osteoporos Int 20(4):567-575

33. Thorisdottir B, Gunnarsdottir I, Palsson GI et al (2013) Protein sources in infancy as predictors for body mass index and IGF-1 concentration at the age of 6 years. Ann Nutr Metab 63:793-793

34. Tsilidis KK, Travis RC, Appleby PN et al (2013) Insulinlike growth factor pathway genes and blood concentrations, 
dietary protein and risk of prostate cancer in the NCI Breast and Prostate Cancer Cohort Consortium (BPC3). Int J Cancer 133(2):495-504

35. Mucci LA, Tamimi R, Lagiou P et al (2001) Are dietary influences on the risk of prostate cancer mediated through the insulin-like growth factor system? Bju Int 87(9):814-820

36. Ma J, Giovannucci E, Pollak M et al (2001) Milk intake, circulating levels of insulin-like growth factor-I, and risk of colorectal cancer in men. J Natl Cancer Inst 93(17):1330-1336

37. Holmes MD, Pollak MN, Willett WC et al (2002) Dietary correlates of plasma insulin-like growth factor I and insulin-like growth factor binding protein 3 concentrations. Cancer Epidemiol Biomark Prev 11(9):852-861

38. Giovannucci E, Pollak M, Liu Y et al (2003) Nutritional predictors of insulin-like growth factor I and their relationships to cancer in men. Cancer Epidemiol Biomark Prev 12(2):84-89

39. Gunnell D, Oliver SE, Peters TJ et al (2003) Are diet-prostate cancer associations mediated by the IGF axis? A cross-sectional analysis of diet, IGF-I and IGFBP-3 in healthy middle-aged men. Br J Cancer 88(11):1682-1686

40. DeLellis K, Rinaldi S, Kaaks RJ et al (2004) Dietary and lifestyle correlates of plasma insulin-like growth factor-I (IGF-I) and IGF binding protein-3 (IGFBP-3): the multiethnic cohort. Cancer Epidemiol Biomark Prev 13(9):1444-1451

41. Hoppe C, Udam TR, Lauritzen L et al (2004) Animal protein intake, serum insulin-like growth factor I, and growth in healthy 2.5-year-old Danish children. Am J Clin Nutr 80(2):447-452

42. Morimoto LM, Newcomb PA, White E et al (2005) Variation in plasma insulin-like growth factor-1 and insulin-like growth factor binding protein-3: Personal and lifestyle factors (United states). Cancer Causes Control 16(8):917-927

43. Rogers I, Emmett P, Gunnell D et al (2006) Milk as a food for growth? The insulin-like growth factors link. Public Health Nutr 9(3):359-368

44. Norat T, Dossus L, Rinaldi S et al (2007) Diet, serum insulinlike growth factor-I and IGF-binding protein-3 in European women. Eur J Clin Nutr 61(1):91-98

45. Budek AZ, Hoppe C, Michaelsen KE et al (2007) Associations of total, dairy, and meat protein with markers for bone turnover in healthy, prepubertal boys. J Nutr 137(4):930-934

46. Crowe FL, Key TJ, Allen NE et al (2009) The Association between diet and serum concentrations of IGF-I, IGFBP-1, IGFBP-2, and IGFBP-3 in the European prospective investigation into cancer and nutrition. Cancer Epidemiol Biomark Prev 18(5):1333-1340

47. Maruyama K, Iso H, Ito $\mathrm{Y}$ et al (2009) Associations of food and nutrient intakes with serum IGF-I, IGF-II, IGFBP-3, TGF-beta 1, Total SOD activity and sFas levels among middle-aged Japanese: the JACC Study. Asian Pac J Cancer Prev 10:6-22

48. Young NJ, Metcalfe C, Gunnell D et al (2012) A cross-sectional analysis of the association between diet and insulin-like growth factor (IGF)-I, IGF-II, IGF-binding protein (IGFBP)-2, and IGFBP-3 in men in the United Kingdom. Cancer Causes Control 23(6):907-917

49. Delellis Henderson K, Rinaldi S, Kaaks R et al (2007) Lifestyle and dietary correlates of plasma insulin-like growth factor binding protein-1 (IGFBP-1), leptin, and C-peptide: the multiethnic cohort. Nutr Cancer 58(2):136-145

50. Cadogan J, Eastell R, Jones N et al (1997) Milk intake and bone mineral acquisition in adolescent girls: randomised, controlled intervention trial. BMJ 315(7118):1255-1260

51. Heaney RP, McCarron DA, Dawson-Hughes B et al (1999) Dietary changes favorably affect bone remodeling in older adults. J Am Diet Assoc 99(10):1228-1233

52. Zhu K, Du XQ, Cowell CT et al (2005) Effects of school milk intervention on cortical bone accretion and indicators relevant to bone metabolism in Chinese girls aged 10-12 years in Beijing. Am J Clin Nutr 81(5):1168-1175

53. Hoppe C, Molgaard C, Juul A et al (2004) High intakes of skimmed milk, but not meat, increase serum IGF-I and IGFBP-3 in eight-year-old boys. Eur J Clin Nutr 58(9):1211-1216

54. Hrolfsdottir L, Rytter D, Bech BH et al (2013) Maternal milk consumption, birth size and adult height of offspring: a prospective cohort study with 20 years of follow-up. Eur J Clin Nutr 67(10):1036-1041

55. Joslowski G, Remer T, Assmann KE et al (2013) Animal protein intakes during early life and adolescence differ in their relation to the growth hormone-insulin-like-growth-factor axis in young adulthood. J Nutr 143(7):1147-1154

56. Signorello LB, Kuper H, Lagiou P et al (2000) Lifestyle factors and insulin-like growth factor 1 levels among elderly men. Eur J Cancer Prev 9(3):173-178

57. Larsson SC, Wolk K, Brismar K et al (2005) Association of diet with serum insulin-like growth factor I in middle-aged and elderly men. Am J Clin Nutr 81(5):1163-1167

58. Ambrosini-Spaltro A, Farnedi A, Montironi R et al (2011) IGFBP2 as an immunohistochemical marker for prostatic adenocarcinoma. Appl Immunohistochem Mol Morphol 19(4):318-328

59. Belharazem D, Kirchner M, Geissler F et al (2012) Relaxed imprinting of IGF2 in peripheral blood cells of patients with a history of prostate cancer. Endocr Connect 1(2):87-94

60. Bhusari S, Yang B, Kueck J et al (2011) Insulin-like growth factor-2 (IGF2) loss of imprinting marks a field defect within human prostates containing cancer. Prostate 71(15):1621-1630

61. Cardillo MR, Monti S, Di Silverio F et al: Insulin-like growth factor (IGF)-I, IGF-II and IGF type I receptor (IGFRI) expression in prostatic cancer. Anticancer Res 2003, 23(5A):3825-3835

62. Chang CF, Pao JB, Yu CC et al (2013) Common variants in IGF1 pathway genes and clinical outcomes after radical prostatectomy. Ann Surg Oncol 20(7):2446-2452

63. Figueroa JA, De Raad S, Tadlock L et al (1998) Differential expression of insulin-like growth factor binding proteins in high versus low Gleason score prostate cancer. J Urol 159(4):1379-1383

64. Hampel OZ, Kattan MW, Yang G et al (1998) Quantitative immunohistochemical analysis of insulin-like growth factor binding protein-3 in human prostatic adenocarcinoma: a prognostic study. J Urol 159(6):2220-2225

65. Hetzl AC, Favaro WJ, Billis A et al (2012) Steroid hormone receptors, matrix metalloproteinases, insulin-like growth factor, and dystroglycans interactions in prostatic diseases in the elderly men. Microsc Res Tech 75(9):1197-1205

66. Hu CK, McCall S, Madden J et al (2006) Loss of heterozygosity of M6P/IGF2R gene is an early event in the development of prostate cancer. Prostate Cancer Prostatic Dis 9(1):62-67

67. Ito K, Yamamoto T, Miyakubo M et al (2009) Impact of insulin-like growth factor (igf) kinetics on the development of prostate cancer: age-adjusted and baseline Psa-adjusted case control study. J Urol 181(4):658-658

68. Johansson M, Mckay JD, Stattin P et al (2007) Comprehensive evaluation of genetic variation in the IGF1 gene and risk of prostate cancer. Int J Cancer 120(3):539-542

69. Lai MT, Chen RH, Tsai FJ et al (2005) Glutathione S-transferase M1 gene but not insulin-like growth factor-2 gene or epidermal growth factor gene is associated with prostate cancer. Urol Oncol 23(4):225-229

70. Latif Z, McMillan DC, Wallace AM et al (2002) The relationship of circulating insulin-like growth factor 1, its binding protein-3, prostate-specific antigen and C-reactive protein with disease stage in prostate cancer. BJU Int 89(4):396-399 
71. Linos KD, Lu S, Ross JS et al (2009) Insulin-Like growth factor binding protein 3 (IGFBP-3) is up-regulated in prostatic adenocarcinoma (PAC) and correlates with gleason grade. Lab Invest 89:179A-179A

72. Liu ZW, Zhou FJ, Luo YM et al (2006) [Genomic imprinting of insulin-like growth factor II in prostate cancer and its clinical significance]. Ai Zheng 25(6):765-770

73. Massoner P, Rennau ML, Heidegger I et al (2011) Expression of the IGF axis is decreased in local prostate cancer but enhanced after benign prostate epithelial differentiation and TGF-beta treatment. Am J Pathol 179(6):2905-2919

74. Mita K, Nakahara M, Usui T (2000) Expression of the insulin-like growth factor system and cancer progression in hormone-treated prostate cancer patients. Int J Urol 7(9):321-329

75. Mucci LA, Stark JR, Pollak MN et al (2010) Plasma levels of acid-labile subunit, free insulin-like growth factor-I, and prostate cancer risk: A Prospective Study. Cancer Epidemiol Biomark Prev 19(2):484-491

76. Okugi H, Koike H, Sekine Y et al (2006) Methylation status of insulin-like growth factor-binding protein-3 promoter in prostate cancer tissues. Asia-Pac J Clin Oncol 2:144-149

77. Oliver SE, Jefferson K, Gunnell D et al (2003) IGF-axis and screen-detected prostate cancer: a cross-sectional study. J Urol 169(4):161-161

78. Paradowska A, Fenic I, Konrad L et al (2009) Aberrant epigenetic modifications in the CTCF binding domain of the IGF2/ H19 gene in prostate cancer compared with benign prostate hyperplasia. Int J Oncol 35(1):87-96

79. Perry AS, Loftus B, Moroose R et al (2007) In silico mining identifies IGFBP3 as a novel target of methylation in prostate cancer. Br J Cancer 96(10):1587-1594

80. Richardsen E, Ukkonen T, Bjornsen T et al (2003) Overexpression of IGBFB2 is a marker for malignant transformation in prostate epithelium. Virchows Arch 442(4):329-335

81. Rowlands MA, Holly JMP, Hamdy F et al (2012) Serum insulin-like growth factors and mortality in localised and advanced clinically detected prostate cancer. Cancer Causes Control 23(2):347-354

82. Ryan CJ, Haqq CM, Simko J et al (2007) Expression of insulin-like growth factor-1 receptor in local and metastatic prostate cancer. Urol Oncol 25(2):134-140

83. Savvani A, Petraki C, Msaouel P et al (2013) IGF-IEc expression is associated with advanced clinical and pathological stage of prostate cancer. Anticancer Res 33(6):2441-2445

84. Seligson DB, Yu H, Tze S et al (2013) IGFBP-3 nuclear localization predicts human prostate cancer recurrence. Horm Cancer 4(1): 12-23

85. Shariat SF, Bergamaschi F, Adler HL et al (2000) Correlation of preoperative plasma IGF-I levels with pathologic parameters and progression in patients undergoing radical prostatectomy. Urology 56(3):423-429

86. Soulitzis N, Karyotis I, Delakas D et al (2006) Expression analysis of peptide growth factors VEGF, FGF2, TGFB1, EGF and IGF1 in prostate cancer and benign prostatic hyperplasia. Int J Oncol 29(2):305-314

87. Stattin P, Soderberg S, Hallmans G et al (2001) Leptin is associated with increased prostate cancer risk: a nested casereferent study. J Clin Endocrinol Metab 86(3):1341-1345

88. Tennant MK, Thrasher JB, Twomey PA et al (1996) Protein and messenger ribonucleic acid (mRNA) for the type 1 insulin-like growth factor (IGF) receptor is decreased and IGF-II mRNA is increased in human prostate carcinoma compared to benign prostate epithelium. J Clin Endocrinol Metab 81(10):3774-3782

89. Thrasher JB, Tennant MK, Twomey PA et al (1996) Immunohistochemical localization of insulin-like growth factor binding proteins 2 and 3 in prostate tissue: clinical correlations. J Urol 155(3):999-1003

90. Tosun Yildirim H, Turk NS (2012) Analysis of imp3 expression in prostate adenocarcinomas. Turk Patoloji Derg 28:128-133

91. Tennant MK, Thrasher JB, Twomey PA et al (1996) Insulin-like growth factor-binding protein-2 and -3 expression in benign human prostate epithelium, prostate intraepithelial neoplasia, and adenocarcinoma of the prostate. J Clin Endocrinol Metab 81(1):411-420

92. Tricoli JV, Winter DL, Hanlon AL et al (1999) Racial differences in insulin-like growth factor binding protein-3 in men at increased risk of prostate cancer. Urology 54(1):178-182

93. Tsuchiya $\mathrm{N}$, Narita $\mathrm{S}$, Inoue $\mathrm{T}$ et al (2013) Insulin-like growth factor-1 genotypes and haplotypes influence the survival of prostate cancer patients with bone metastasis at initial diagnosis. BMC Cancer 13:150

94. Tsuchiya N, Wang L, Suzuki H et al (2006) Impact of IGF-I and CYP19 gene polymorphisms on the survival of patients with metastatic prostate cancer. J Clin Oncol 24(13):1982-1989

95. Tu SM, Kim J, Wang XM et al (2004) Validating insulin-like growth factor (IGF)-1 and IGF binding protein (IGFBP)-3 as pertinent therapeutic targets for advanced prostate cancer. $\mathrm{J}$ Bone Miner Res 19(9):1585-1585

96. Turney BW, Turner GDH, Brewster SF et al (2011) Serial analysis of resected prostate cancer suggests up-regulation of type 1 IGF receptor with disease progression. BJU Int 107(9):1488-1499

97. Woongeol Y, Kwanjin P, Seong Jin J et al (2007) Relation of plasma IGF-1 and IGFBP-3 to the risk of prostate cancer. Eur Urol Suppl 6(2):149-149

98. Yu H, Nicar MR, Shi RH et al (2001) Levels of insulin-like growth factor 1 (IGF-I) and IGF binding proteins 2 and 3 in serial postoperative serum samples and risk of prostate cancer recurrence. Urol 57(3):471-475

99. Zu K, Martin NE, Fiorentino M et al (2013) Protein expression of pten, insulin-like growth factor i receptor (igf-ir), and lethal prostate cancer: A Prospective Study. Cancer Epidemiol Biomark Prev 22(11):1984-1993

100. Lisitskaia KV, Krakhmaleva IN, Shishkin SS (2010) A study of the single nucleotide polymorphism in seven genes (GHR, IGFBP3, IGFR1, IRS1, FMN1, ANXA2, TaGLN) in ethnic Russians and in patients with prostate cancer. Mol Gen Microbiol Virol 25(2):34-37

101. Wolk A, Mantzoros CS, Andersson SO et al (1998) Insulin-like growth factor 1 and prostate cancer risk: a population-based, case-control study. J Natl Cancer Inst 90(12):911-915

102. Djavan B, Bursa B, Seitz C et al (1999) Insulin-like growth factor 1 (IGF-1), IGF-1 density, and IGF-1/PSA ratio for prostate cancer detection. Urology 54(4):603-606

103. Hill M, Bilek R, Safarik L et al (2000) Analysis of relations between serum levels of epitestosterone, estradiol, testosterone, IGF-1 and prostatic specific antigen in men with benign prostatic hyperplasia and carcinoma of the prostate. Physiol Res 49:S113-S118

104. Koliakos G, Chatzivasiliou D, Dimopoulos T et al (2000) The significance of PSA/IGF-1 ratio in differentiating benign prostate hyperplasia from prostate cancer. Dis Markers 16(3-4):143-146

105. Ismail $\mathrm{H}$, Pollak $\mathrm{M}$, Behlouli $\mathrm{H}$ et al (2002) Insulin-like growth factor- 1 and insulin-like growth factor binding protein-3 for prostate cancer detection in patients undergoing prostate biopsy. J Urol 168(6):2426-2430

106. Miyata Y, Sakai H, Hayashi T (2003) Serum insulin-like growth factor binding protein-3/prostate-specific antigen ratio is a useful predictive marker in patients with advanced prostate cancer. Prostate 54(2):125-132 
107. Scorilas A, Plebani M, Mazza S et al (2003) Serum human glandular kallikrein (hK2) and insulin-like growth factor I (IGF-I) improve the discrimination between prostate cancer and benign prostatic hyperplasia in combination with total and \%free PSA. Prostate 54(3):220-229

108. Aksoy Y, Aksoy H, Bakan E et al (2004) Serum insulin-like growth factor-I and insulin-like growth factor-binding protein-3 in localized, metastasized prostate cancer and benign prostatic hyperplasia. Urol Int 72(1):62-65

109. Nam RK, Trachtenberg J, Jewett MAS et al (2005) Serum insulin-like growth factor-I levels and prostatic intraepithelial neoplasia: a clue to the relationship between IGF-I physiology and prostate cancer risk. Cancer Epidemiol Biomark Prev 14(5):1270-1273

110. Trojan L, Bode C, Weiss C et al (2006) IGF-II serum levels increase discrimination between benign prostatic hyperplasia and prostate cancer and improve the predictive value of PSA in clinical staging. Eur Urol 49(2):286-292

111. Hong SK, Han BK, Jeong JS et al (2008) Serum measurements of testosterone, insulin-like growth factor 1 , and insulin-like growth factor binding protein-3 in the diagnosis of prostate cancer among Korean men. Asian J Androl 10(2):207-213

112. Sciarra A, Gentile V, Monti S et al (2008) Comparison of chromogranin A, insulin-like growth factor 1 and prostate-specific antigen serum markers in prostate adenocarcinoma and benign prostatic hyperplasia. Urol Int 80(1):68-73

113. Pina FM, Figueiredo G, Lunet $\mathrm{N}$ et al (2009) Association between IGF-I and prostatitis, PIN III and prostate cancer diagnosis. Urology 74(4): 150

114. Tajtakova M, Pidanicova A, Valansky L et al (2010) Serum level of IGFBP3 and IGF1/IGFBP3 molar ratio in addition to PSA and single nucleotide polymorphism in PSA and CYP17 gene may contribute to early diagnostics of prostate cancer. Neoplasma 57(2):118-122

115. Darago A, Sapota A, Matych J et al (2011) The correlation between zinc and insulin-like growth factor 1 (IGF-1), its binding protein (IGFBP-3) and prostate-specific antigen (PSA) in prostate cancer. Clin Chem Lab Med 49(10):1699-1705

116. Khosravi J, Diamandi A, Mistry J et al (2001) Insulin-like growth factor I (IGF-I) and IGF-binding protein-3 in benign prostatic hyperplasia and prostate cancer. J Clin Endocrinol Metab 86(2):694-699

117. Baffa R, Reiss K, El-Gabry EA et al (2000) Low serum insulinlike growth factor 1 (IGF-1): a significant association with prostate cancer. Tech Urol 6(3):236-239

118. Harman SM, Metter EJ, Blackman MR et al (2000) Serum levels of insulin-like growth factor I (IGF-I), IGF-II, IGF-binding protein-3, and prostate-specific antigen as predictors of clinical prostate cancer. J Clin Endocrinol Metab 85(11):4258-4265

119. Stattin P, Bylund A, Rinaldi S et al (2000) Plasma insulin-like growth factor-I, insulin-like growth factor-binding proteins, and prostate cancer risk: a Prospective Study. J Natl Cancer Inst 92(23):1910-1917

120. Li L, Yu H, Schumacher F et al (2003) Relation of serum insulin-like growth factor-I (IGF-I) and IGF binding protein-3 to risk of prostate cancer (United States). Cancer Causes Control 14(8):721-726

121. Woodson K, Tangrea JA, Pollak M et al (2003) Serum insulinlike growth factor 1: tumor marker or etiologic factor? A prospective study of prostate cancer among Finnish men. Cancer Res 63(14):3991-3994

122. Janssen JAMJL, Wildhagen MF, Ito $\mathrm{K}$ et al (2004) Circulating free insulin-like growth factor (IGF)-I, total IGF-I, and IGF binding protein-3 levels do not predict the future risk to develop prostate cancer: results of a case-control study involving 201 patients within a population-based screening with a 4-year interval. J Clin Endocrinol Metab 89(9):4391-4396

123. Stattin P, Rinaldi S, Biessy C et al (2004) High levels of circulating insulin-like growth factor-I increase prostate cancer risk: a Prospective Study in a population-based nonscreened cohort. J Clin Oncol 22(15):3104-3112

124. Chen C, Lewis SK, Voigt L et al (2005) Prostate carcinoma incidence in relation to prediagnostic circulating levels of insulin-like growth factor I, insulin-like growth factor binding protein 3, and insulin. Cancer 103(1):76-84

125. Meyer F, Galan P, Douville P et al (2005) A prospective study of the insulin-like growth factor axis in relation with prostate cancer in the SU.VI.MAX trial. Cancer Epidemiol Biomark Prev 14(9):2269-2272

126. Platz EA, Pollak MN, Leitzmann MF et al (2005) Plasma insulin-like growth factor- 1 and binding protein-3 and subsequent risk of prostate cancer in the PSA era. Cancer Causes Control 16(3):255-262

127. Morris BL, Young T, Van Golen CM: IGF-IR inibition induces MAPK signaling in prostate carcinoma cells. Cancer Res 2011, 71(8 (suppl)):2924 (Abstract)

128. Allen NE, Key TJ, Appleby PN et al (2007) Serum insulinlike growth factor (IGF)-I and IGF-binding protein-3 concentrations and prostate cancer risk: results from the European prospective investigation into cancer and nutrition. Cancer Epidemiol Biomark Prev 16(6):1121-1127

129. Li H, Bubley GJ, Balk SP et al (2007) Hypoxia-inducible factor-1alpha (HIF-1alpha) gene polymorphisms, circulating insulin-like growth factor binding protein (IGFBP)-3 levels and prostate cancer. Prostate 67(12):1354-1361

130. Weiss JM, Huang WY, Rinaldi S et al (2007) IGF-1 and IGFBP-3: Risk of prostate cancer among men in the prostate, lung, colorectal and ovarian cancer screening trial. Int J Cancer 121(10):2267-2273

131. Mikami K, Ozasa K, Nakao M et al (2009) Prostate cancer risk in relation to insulin-like growth factor (IGF)-I and IGFbinding protein-3: A Nested Case-Control Study in Large Scale Cohort Study in Japan (JACC Study). Asian Pac J Cancer Prev 10:57-61

132. Nimptsch K, Platz EA, Pollak MN et al (2011) Plasma insulin-like growth factor 1 is positively associated with lowgrade prostate cancer in the Health Professionals Follow-up Study 1993-2004. Int J Cancer 128(3):660-667

133. Price AJ, Allen NE, Appleby PN et al (2012) Insulin-like growth factor-i concentration and risk of prostate cancer: results from the European prospective investigation into cancer and nutrition. Cancer Epidemiol Biomark Prev 21(9):1531-1541

134. Muhlbradt E, Ma J, Severi G et al (2013) Variant NKX3.1 and Serum IGF-1: investigation of interaction in prostate cancer. Genes Cancer 4(11-12):535-545

135. Cohen P, Peehl DM, Stamey TA et al (1993) Elevated levels of insulin-like growth factor-binding protein-2 in the serum of prostate-cancer patients. J Clin Endocrinol Metab 76(4):1031-1035

136. Mantzoros CS, Tzonou A, Signorello LB et al (1997) Insulinlike growth factor 1 in relation to prostate cancer and benign prostatic hyperplasia. Br J Cancer 76(9):1115-1118

137. Signorello LB, Brismar K, Bergstrom R et al (1999) Insulinlike growth factor-binding protein-1 and prostate cancer. J Natl Cancer Inst 91(22): 1965-1967

138. Finne P, Auvinen A, Koistinen $\mathrm{H}$ et al (2000) Insulin-like growth factor I is not a useful marker of prostate cancer in men with elevated levels of prostate-specific antigen. J Clin Endocrinol Metab 85(8):2744-2747 
139. Kurek R, Tunn UW, Eckart O et al (2000) The significance of serum levels of insulin-like growth factor-1 in patients with prostate cancer. BJU Int 85(1):125-129

140. Lacey JV, Hsing AW, Fillmore CM et al (2001) Null association between insulin-like growth factors, insulin-like growth factorbinding proteins, and prostate cancer in a prospective study. Cancer Epidemiol Biomark Prev 10(10):1101-1102

141. Chokkalingam AP, Pollak M, Fillmore CM et al (2001) Insulin-like growth factors and prostate cancer: a population-based case-control study in China. Cancer Epidemiol Biomark Prev 10(5):421-427

142. Li L, Liu J, Anwu T: Significance of determination of serum insulin-like growth factor 1 (IGF- I) in prostate cancer. Tianjin : Tianjin-shi Tixue She 2001.

143. Oliver SE, Gunnell D, Donovan J et al (2004) Screen-detected prostate cancer and the insulin-like growth factor axis: results of a Population-Based Case-Control Study. Int J Cancer 108(6):887-892

144. Marszalek M, Wachter J, Ponholzer A et al (2005) Insulin-like growth factor 1, chromogranin A and prostate specific antigen serum levels in prostate cancer patients and controls. Eur Urol 48(1):34-39

145. Hernandez W, Grenade C, Santos ER et al (2007) IGF-1 and IGFBP-3 gene variants influence on serum levels and prostate cancer risk in African-Americans. Carcinogenesis 28(10):2154-2159

146. Zhao ZG, Liu JM, Li S et al (2007) Serum insulin-like growth factor $\mathrm{I} /$ free prostate specific antigen (IGF-I/fPSA) ratio enhances prostate cancer detection in men with total PSA 4.0 $10.0 \mathrm{ng} / \mathrm{ml}$. J Surg Oncol 96(1):54-61

147. Borugian MJ, Spinelli JJ, Sun Z et al (2008) Prostate cancer risk in relation to insulin-like growth factor (IGF)-I and IGF-binding protein-3: a Prospective Multiethnic Study. Cancer Epidemiol Biomark Prev 17(1):252-254

148. Kim JH, Park KJ, Bae J-B et al (2009) Plasma insulin-like growth factor-1 (IGF-1), IGF-binding protein-3, and the risk of prostate cancer: a Matched Case-Control Study in a Korean population. Korean J Urol 50(7):645-648

149. Johansson M, McKay JD, Rinaldi S et al (2009) Genetic and plasma variation of insulin-like growth factor binding proteins in relation to prostate cancer incidence and survival. Prostate 69(12):1281-1291

150. Gill JK, Wilkens LR, Pollak MN et al (2010) Androgens, growth factors, and risk of prostate cancer: the multiethnic cohort. Prostate 70(8):906-915

151. Kim JH, Lee SW, Jeong SJ et al (2010) The joint association of plasma 1, 25-dihydroxyvitamin D3 and IGFBP-3 levels and VDR FOK1 polymorphism with prostate cancer risk in Korean men. Eur Urol Suppl 9(2):243

152. Park K, Kim JH, Jeon HG et al: Influence of IGFBP3 gene polymorphisms on IGFBP3 serum levels and the risk of prostate cancer in low-risk Korean men. Urology 2010, 75(6)

153. Campa D, Husing A, Chang-Claude J et al (2011) Genetic variability of the fatty acid synthase pathway is not associated with prostate cancer risk in the European prospective investigation on cancer (EPIC). Eur J Cancer 47(3):420-427

154. Neuhouser ML, Platz EA, Till C et al (2013) Insulin-like growth factors and insulin-like growth factor-binding proteins and prostate cancer risk: results from the prostate cancer prevention trial. Cancer Prev Res 6(2):91-99

155. Chan JM, Stampfer MJ, Giovannucci E et al (1998) Plasma insulin-like growth factor I and prostate cancer risk: a prospective study. Science 279(5350):563-566

156. Kaaks R, Lukanova A, Rinaldi $S$ et al (2003) Interrelationships between plasma testosterone, SHBG, IGF-I, insulin and leptin in prostate cancer cases and controls. Eur J Cancer Prev 12(4):309-315

157. Stattin P, Stenman UH, Riboli E et al (2001) Ratios of IGF-I, IGF binding protein-3, and prostate-specific antigen in prostate cancer detection. J Clin Endocrinol Metab 86(12):5745-5748

158. Chan JM, Stampfer MJ, Ma J et al (2002) Insulin-like growth factor-I (IGF-I) and IGF binding protein-3 as predictors of advanced-stage prostate cancer. J Natl Cancer Inst 94(14):1099-1106

159. Gu FY, Schumacher FR, Canzian F et al (2010) Eighteen insulin-like growth factor pathway genes, circulating levels of IGF-I and its binding protein, and risk of prostate and breast cancer. Cancer Epidemiol Biomark Prev 19(11):2877-2887

160. Tsilidis KK, Travis RC, Appleby PN et al (2012) Interactions between genome-wide significant genetic variants and circulating concentrations of insulin-like growth factor 1, sex hormones, and binding proteins in relation to prostate cancer risk in the national cancer institute breast and prostate cancer cohort consortium. Am J Epidemiol 175(9):926-935

161. Ho GYF, Melman A, Liu SM et al (2003) Polymorphism of the insulin gene is associated with increased prostate cancer risk. Br J Cancer 88(2):263-269

162. Wang LZ, Habuchi T, Tsuchiya $N$ et al (2003) Insulin-like growth factor-binding protein-3 gene-202 $\mathrm{A} / \mathrm{C}$ polymorphism is correlated with advanced disease status in prostate cancer. Cancer Res 63(15):4407-4411

163. Li L, Cicek MS, Casey G et al (2004) No association between genetic Polymorphisms in 1GF-1 and IGFBP-3 and prostate cancer. Cancer Epidemiol Biomark Prev 13(3):497-498

164. Friedrichsen DM, Hawley S, Shu J et al (2005) IGF-I and IGFBP-3 polymorphisms and risk of prostate cancer. Prostate 65(1):44-51

165. Tsuchiya N, Wang LH, Horikawa Y et al (2005) CA repeat polymorphism in the insulin-like growth factor-I gene is associated with increased risk of prostate cancer and benign prostatic hyperplasia. Int J Oncol 26(1):225-231

166. Chen C, Freeman R, Voigt LF et al (2006) Prostate cancer risk in relation to selected genetic polymorphisms in insulin-like growth factor-1, insulin-like growth factor binding protein-3, and insulin-like growth factor-I receptor. Cancer Epidemiol Biomark Prev 15(12):2461-2466

167. Hoyo C, Grubber J, Demark-Wahnefried W et al (2007) Gradespecific prostate cancer associations of IGF1(CA)(19) repeats and IGFBP3-202A/C in Blacks and whites. J Natl Med Assoc 99(7):718-722

168. Schumacher FR, Cheng I, Freedman ML et al (2010) A comprehensive analysis of common IGF1, IGFBP1 and IGFBP3 genetic variation with prospective IGF-I and IGFBP-3 blood levels and prostate cancer risk among. Hum Mol Genet 19(15):3089-3101

169. Neuhausen SL, Slattery ML, Garner CP et al (2005) Prostate cancer risk and IRS1, IRS2, IGF1, and INS polymorphisms: Strong association of IRS1 G972R variant and cancer risk. Prostate 64(2):168-174

170. Schildkraut JM, Demark-Wahnefried W, Wenham RM et al (2005) IGF1 (CA)(19) repeat and IGFBP3-202A/C genotypes and the risk of prostate cancer in black and white men. Cancer Epidemiol Biomark Prev 14(2):403-408

171. Cheng I, Stram DO, Penney KL et al (2006) Common genetic variation in IGF1 and prostate cancer risk in the Multiethnic Cohort. J Natl Cancer Inst 98(2):123-134

172. Cheng I, Penney KL, Stram DO et al (2006) Haplotype-based association studies of IGFBP1 and IGFBP3 with prostate and breast cancer risk: the multiethnic cohort. Cancer Epidemiol Biomark Prev 15(10):1993-1997 
173. Johansson M, Mckay JD, Wiklund $F$ et al (2007) Implications for prostate cancer of insulin-like growth factor-I (IGF-I) genetic variation and circulating IGF-I levels. J Clin Endocrinol Metab 92(12):4820-4826

174. Shariat SF, Lamb DJ, Kattan MW et al (2002) Association of preoperative plasma levels of insulin-like growth factor I and insulin-like growth factor binding proteins- 2 and -3 with prostate cancer invasion, progression, and metastasis. J Clin Oncol 20(3):833-841

175. Severi G, Morris HA, MacInnis RJ et al (2006) Circulating insulin-like growth factor-I and binding protein-3 and risk of prostate cancer. Cancer Epidemiol Biomark Prev 15(6):1137-1141

176. Kanety H, Madjar Y, Dagan Y et al (1993) Serum insulin-like growth factor-binding protein-2 (Igfbp-2) is increased and Igfbp-3 is decreased in patients with prostate-cancer - correlation with serum prostate-specific antigen. J Clin Endocrinol Metab 77(1):229-233

177. Ho PJ, Baxter RC (1997) Insulin-like growth factor-binding protein-2 in patients with prostate carcinoma and benign prostatic hyperplasia. Clin Endocrinol 46(3):333-342

178. Cutting CWM, Hunt C, Nisbet JA et al (1999) Serum insulinlike growth factor- 1 is not a useful masker of prostate cancer. Bju Int 83(9):996-999

179. Perk H, Serel TA, Delibas N et al (2001) Prostatic fluid-free insulin-like growth factor-1 in relation to prostate cancer. Bju Int 88(9):946-949

180. Peng L, Tang S, Xie J (2002) Quantitative analysis of IGF-1 and its application in the diagnosis of prostate cancer. Hua-Hsi i Ko Ta Hsueh Hsueh Pao [Journal of West China University of Medical Sciences] 33:137-139

181. Trapeznikova MF, Shibaeva AN, Ianshin A (2004) Vascular endothelium growth factor and insulin-like growth factors in prostatic cancer. Urologiya 1:17-21

182. Lopez JB, Sahabudin RM, Chin LP (2004) Are plasma insulin-like growth factor I (IGF-I) and IGF-binding protein 3 (IGFBP-3) useful markers of prostate cancer? Int J Biol Markers 19(2):164-167

183. Kehinde EO, Akanji AO, Mojiminiyi OA et al (2005) Putative role of serum insulin-like growth factor-1 (IGF-1) and IGF binding protein-3 (IGFBP-3) levels in the development of prostate cancer in Arab men. Prostate Cancer Prostatic Dis $8(1): 84-90$

184. Iltaf M, Jagdesh, Panjwani JP et al (2013) Trait marker IGF1 is more diagnostic than PSA in Ca prostate, study at local population of Karachi. Pak J Med Health Sci 7:626-629

185. Sarma AV, Dunn RL, Lange LA et al (2008) Genetic polymorphisms in CYP17, CYP3A4, CYP19A1, SRD5A2, IGF-1, and IGFBP-3 and prostate cancer risk in African-American men: The flint men's health study. Prostate 68(3):296-305

186. Silha JV, Sheppard PC, Mishra S et al (2006) Insulin-like growth factor (IGF) binding protein-3 attenuates prostate tumor growth by IGF-dependent and IGF-independent mechanisms. Endocrinology 147(5):2112-2121
187. Sutherland BW, Knoblaugh SE, Kaplan-Lefko PJ et al (2008) Conditional deletion of insulin-like growth factor-I receptor in prostate epithelium. Cancer Res 68(9):3495-3504

188. Anzo M, Cobb LJ, Hwang DL et al (2008) Targeted deletion of hepatic Igf1 in TRAMP mice leads to dramatic alterations in the circulating insulin-like growth factor axis but does not reduce tumor progression. Cancer Res 68(9):3342-3349

189. Mehta HH, Gao QL, Galet C et al (2011) IGFBP-3 is a metastasis suppression gene in prostate cancer. Cancer Res 71(15):5154-5163

190. Goya M, Miyamoto S, Nagai K et al (2004) Growth inhibition of human prostate cancer cells in human adult bone implanted into nonobese diabetic/severe combined immunodeficient mice by a ligand-specific antibody to human insulin-like growth factors. Cancer Res 64(17):6252-6258

191. Wu JD, Odman A, Higgins LM et al (2005) In vivo effects of the human type I insulin-like growth factor receptor antibody A12 on androgen-dependent and androgen-independent xenograft human prostate tumors. Clin Cancer Res 11(8):3065-3074

192. Ingermann AR, Yang YF, Han JF et al (2010) Identification of a novel cell death receptor mediating IGFBP-3-induced anti-tumor effects in breast and prostate cancer. J Biol Chem 285(39):30233-30246

193. Kimura T, Kuwata T, Ashimine S et al (2010) Targeting of bone-derived insulin-like growth factor-ii by a human neutralizing antibody suppresses the growth of prostate cancer cells in a human bone environment. Clin Cancer Res 16(1):121-129

194. DiGiovanni J, Kiguchi K, Frijhoff A et al (2000) Deregulated expression of insulin-like growth factor 1 in prostate epithelium leads to neoplasia in transgenic mice. Proc Natl Acad Sci USA 97(7):3455-3460

195. Fu VX, Dobosy JR, Dosetelle JA et al (2008) Aging-related loss of insulin-like growth factor-2 (Igf2) imprinting in the prostate. J Urol 179(4):394-394

196. Martin RM, Holly JMP, Gunnell D (2011) Milk and linear growth: programming of the IGF-I axis and implication for health in adulthood. Milk Milk Prod Hum Nutr 67:79-97

197. Tsilidis KK, Papatheodorou SI, Evangelou E et al (2012) Evaluation of excess statistical significance in meta-analyses of 98 biomarker associations with cancer risk. J Natl Cancer Inst 104(24): 1867-1878

198. Ramos-Levi AM, Marazuela M, Paniagua A et al (2015) Analysis of IGF(CA)19 and IGFBP3-202A/C gene polymorphisms in patients with acromegaly: association with clinical presentation and response to treatments. Eur J Endocrinol 172(2):115-122

199. Bonilla C, Lewis SJ, Rowlands MA et al (2016) Assessing the role of insulin-like growth factors and binding proteins in prostate cancer using Mendelian randomization: genetic variants as instruments for circulating levels. Int $\mathrm{J}$ Cancer 139(7):1520-1533 